ASSESSMENT OF ALTERNATIVE MANUAL CONTROL METHODS FOR SMALL UNMANNED AERIAL VEHICLES

\begin{tabular}{|r|l|}
\hline Journal: & Journal of Unmanned Vehicle Systems \\
\hline Manuscript ID & juvs-2015-0007.R1 \\
\hline Manuscript Type: & Article \\
\hline Date Submitted by the Author: & $13-$ May-2015 \\
\hline Kemplete List of Authors: & $\begin{array}{l}\text { Stevenson, Jonathan; Memorial University, Faculty of Engineering } \\
\text { O'Young, Siu; Memorial University of Newfoundland, Faculty of Engineering } \\
\text { and Applied Science } \\
\text { Rolland, Luc; Memorial University, Engineering }\end{array}$ \\
\hline & \multicolumn{2}{|l}{} \\
\hline
\end{tabular}




\title{
ASSESSMENT OF ALTERNATIVE MANUAL CONTROL METHODS FOR SMALL UNMANNED AERIAL VEHICLES
}

\author{
Jonathan D. Stevenson \\ Memorial University \\ St. John's, NL, Canada
}

\author{
Dr. Siu O'Young \\ Memorial University \\ St. John's, NL, Canada
}

\author{
Dr. Luc Rolland \\ Memorial University \\ St. John's, NL, Canada
}

\begin{abstract}
This paper is a summary of experiments to assess alternative methods to control a small $(<25 \mathrm{~kg})^{1}$ Unmanned Aerial Vehicle (UAV) in manual mode. While it is true that the majority of a typical UAV mission will be in automatic mode (i.e. using an autopilot) this may not always be the case during takeoffs and landings, or if there is a failure of the autopilot. The concept of a manual control backup mode during all flight phases remains in proposed UAV regulations currently being defined in Canada and the U.S. The research summarized in this paper is an attempt to assess the accuracy of several manual control options for a small UAV. The paper includes both a theoretical discussion of the task of manually controlling a small UAV airframe and results from a series of field experiments investigating the use of First-Person View techniques.
\end{abstract}

\subsection{INTRODUCTION}

Since 2005 our research group has been experimenting with technologies and operational methods with the aim to improve the reliability and safety of small UAVs when under manual control. This paper will provide a summary of the results from these efforts to date. Improvements may be possible in terms of improved control accuracy and enhanced situational awareness of the pilot while flying in manual mode, resulting in improved safety.

If we survey the current situation with UAVs for all sizes of UAVs, we find that similar control methods are common throughout. The most common methods, grouped into Automatic or Manual Control modes are:

1. Automatic Control:

a. GPS-based Autopilot (AP) control using waypoints to define a flight plan;

b. Inertial, airspeed and pressure sensors used for attitude, airspeed and altitude control (i.e. inner-loop airframe control); and,

c. Limited Automatic Take-off and Landing (ATOL) capabilities offered by some autopilots.

d. Autonomous Control (research activity at present) ${ }^{2}$

2. Manual Control:

a. Radio Control (R/C) Aircraft methods by an External Pilot (EP) using un-aided third person visual view of the remote UAV, commonly used with small UAVs;

b. A Flight Console, similar to a dual-pilot cockpit, using a forward fixed camera view to allow a Manual Pilot (MP) to fly the UAV as in a simulator. This mode is especially popular with military UAVs like the Predator; and,

c. Virtual Reality (VR) methods employing various forms of First Person View (FPV) flying. This has become popular in recent years as an alternative to the more traditional R/C third-person view (DJI 2013).

While it is true that some autopilots provide an Automatic Takeoff and Landings (ATOL) capability, manual control methods are more common with small UAVs. This is in spite of the fact that a careful review of available UAV accident reports revealed that the majority of UAV accidents occur during take-off and landing, especially by UAVs which rely on a manual pilot to accomplish these tasks (Williams 2004). The reason why ATOL is avoided is the difficulty in obtaining a reliable control system, especially with small airframes, given the limited accuracy of most low-cost autopilots. This generally results in poor-quality and at times hazardous automated landings ${ }^{3}$. In most cases, it is deemed easier and safer to have a highly-skilled EP conduct the takeoffs and landings. A

\footnotetext{
${ }^{1}$ Under Transport Canada rules, small UAV are classified as under $25 \mathrm{~kg}$ (Transport Canada 2014).

${ }^{2}$ A distinction must be made between the Automatic Control modes offered by most UAV autopilots and Autonomous Control. With Automatic Control the UAV simply is able to follow its pre-programmed flight plan. Autonomous Control implies the UAV is able to "think" and response dynamically to its environment without human intervention or assistance. Such a capability remains an active research area, and indeed is a major component of a DSA capability, but as yet is unavailable in currently operational UAV systems.

${ }^{3}$ The focus will be only on runway-based "roll-on/roll-off" landings. Other modes of landings, e.g. with nets, parachutes or deep stalls will not be considered.
} 
similar reluctance to use ATOL is evident in larger UAVs such as the Predator. The Predator requires that a highly-trained UAV pilot conduct the landings and takeoff at a forward Ground Control Station (GCS), before passing off control to a remote GCS which might be located on the other side of the world (Hodges 2009).

For a small UAV a typical mission will most likely progress through these flight stages:

1. Takeoff (Manual Control)

2. Transition to Automatic Control

3. Autonomous Flight (AP in control)

4. Transition back to Manual Control

5. Landing

The External Pilot (EP) will conduct the take-off and climb to a pre-selected altitude and establish a stable loiter circuit over the launch site (Stage 1). Once airborne and at a stable altitude and flight condition, control will be switched to automatic control (Stage 2). Once stable AP control is confirmed, the UAV will now fly its mission relying on an on-board autopilot (AP), though with supervisory control by an Air Vehicle Operator (AVO) located at the Ground Control Station (Stage 3). At the conclusion of the mission, the UAV will fly to its recovery airbase, and once in visual range and ready to land, control will be switched back to manual control (Stage 4). The EP will then resume control of the UAV and land it manually (Stage 5).

It should be noted that even if a fully-automatic UAV control capability were provided (i.e. including ATOL) there will still be a requirement for an EP according to current and proposed Transport Canada UAV operating guidelines, ready to assume manual control of the UAV as needed, especially if there is a failure of the autopilot. All Special Flight Operation Certificates (SFOC) obtained to date by our research team have required the presence of one EP for each airborne UAV (Transport Canada 2010). Very recent Canadian (Transport Canada 2014) and U.S. (FAA 2015) regulations regarding UAV operations are trending towards the notion that every UAV will have a primary pilot equivalent to a Pilot in Command (PIC). This PIC would have the final authority over airborne UAV flights and would be the person responsible for safety. This requirement includes the capability to assume manual control at all flight stages, similar to manned aircraft operations.

Providing a manual override capability at all stages of UAV operations is a challenge, especially when operations at Beyond Visual Line of Sight (BVLOS) ranges or in non-visual flying conditions are considered. For example, if basic R/C methods employing unassisted third-person flying techniques are used, effective manual control is limited to at most $1 \mathrm{~km}$ and only under benign daytime visual weather conditions. The lack of a viable BVLOS manual control method is cited as one of the major limitations to the operational range of small UAVs in the current regulatory environment, the other hurdle being the lack of a reliable Detect Sense and Avoid (DSA) system (Ellis 2006). It is clear that some form of enhancement is needed to provide an effective manual control of the small UAV at all operational ranges. The suitability of the basic R/C flying method (i.e. using a remote, un-assisted, third person view) has also been questioned (Williams 2004). Research efforts have been expended to investigate these problems and to find possible solutions, including:

1. Experiments using Virtual Reality (VR) to pilot small UAVs using a First-Person View (FPV) during the critical landing stage of flight;

2. Extended range video links to allow manual override control beyond normal visual range; and,

3. Using a synthetic environment as a visual enhancement at BVLOS ranges or otherwise when high speed good quality video is not available.

This paper will present the results from the VR Experiments, beginning with a theoretical analysis of the manual control of a small UAV.

\subsection{NOMENCLATURE}

\section{ANOVA Analysis of Variance}

AP Autopilot

ATOL Automatic Take-off and Landing

AVO Autonomous Vehicle Operator

BVLOS Beyond Visual Line of Sight

CARs Canadian Aviation Regulations

DOE Design of Experiments 


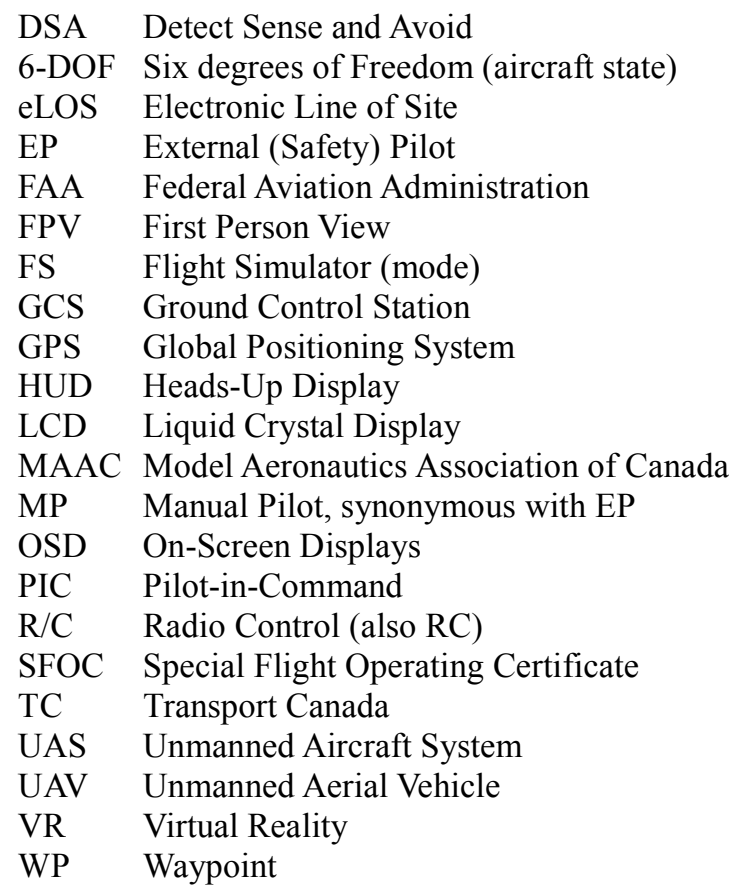

\subsection{ANALYSIS OF MANUAL UAV CONTROL}

In this section, an analysis will be made of the piloting modes involved when flying a small UAV under manual control.

\subsection{Summary of the Manual Control Situation}

When we consider how an External Pilot (EP) flies a small UAV using a third person R/C view, we might consider the situation as shown in Error! Reference source not found. The pilot must control the three principle position angles of the aircraft (i.e. roll, pitch and yaw) using the flight controls at his disposal to manipulate the ailerons, elevator, and rudder respectively, plus throttle to maintain altitude and airspeed. At the same time he must also control the position of the aircraft in 3-D space, in terms of its horizontal position $(\mathrm{X} / \mathrm{Y})$, altitude $(\mathrm{Z})$, plus heading and velocity.

\section{$<$ figure 1 here $>$}

The pilot must manage in excess of 8 variables in real time from a remote vantage point, through spatial references, depth perception and other visual cues. This must be accomplished in real-time simultaneously, quickly yet smoothly, to maintain good positive control of the UAV. If we add the extra problem of spatial disorientation caused by the aircraft being in an abnormal attitude (e.g. upside down, pointing straight up, etc.), or the control reversal phenomenon when the aircraft is flying towards you, the difficulty of the EP problem becomes clear. Often $\mathrm{R} / \mathrm{C}$ aircraft are destroyed by this control reversal phenomenon, especially due to improper rudder or aileron control inputs. There is also the problem of what happens if the aircraft flies too far away or in difficult lighting conditions (e.g. into bright sun, silhouetted against clouds, etc.). The latter can make it difficult if not impossible to determine the UAV's orientation, which leads to incorrect control inputs and the risk of going out of control.

\subsection{First Person versus Third Person View}

If the EP switches to a First Person View (FPV) several things happen. The pitch, roll and yaw of the aircraft are now directly connected to the pilot's forward view. In a sense, the aircraft becomes an extension of his or her body. The need to do the rapid assessment of orientation using an external view is eliminated. The pilot can now focus on the key parameters of flight - maintaining heading, altitude and airspeed. The control of pitch, roll and yaw becomes instinctual. The control task is reduced by at least three variables, and perhaps as much as six. The incorporation of the FPV view should therefore improve the controllability of the airframe. However, it must be recognized this benefit only applies if the UAV pilot is already familiar with the basics of good airmanship. The dynamics of the aircraft and any control delays must also be considered. 


\subsection{The Effect of Control Delays}

The task of flying a small UAV using manual methods is closely linked to the dynamics of the airframe being controlled and any control delays that are imposed. If these delays or the aircraft dynamics become extreme, accurate manual control becomes very difficult or impossible.

An analysis can be done to quantify the sources of control delay during manual piloting. Three different methods for manually piloting a small UAV are shown schematically in Figure 2, with annotations showing the sources of these delays.

$<$ figure 2 here $>$

The total control lag will vary considerably depending on the form of remote manual control used. Taking a very simple view, the total lag will be the sum of each of the sub-element delays:

$$
\tau_{\text {delay }}=\tau_{\text {pilot }}+\tau_{\mathrm{a} / \mathrm{c}}+\tau_{\text {comm }}+\tau_{\text {gcs }}
$$

Where each term is detailed below:

$\tau_{\text {pilot }}=$ Human Operator (pilot) Reaction Time. The major contributor to manual control lag is the reaction time of the pilot. Typical human reaction times to simple stimuli have been measured and range from 150 to $300 \mathrm{~ms}$, with $250 \mathrm{~ms}$ being typical. Age, environmental conditions (e.g. light level), fatigue and general situational awareness are factors in determining the reaction time for a specific person. Highly trained individuals such as athletes and pilots can condition themselves to improve this reaction time, although consistently, the best reaction time is on average $180 \mathrm{~ms}$ (McCormick 1970). Note that these are reaction times to expected events. Reactions to unexpected events can be much slower. The average reaction time in this situation is commonly quoted in the literature as $750 \mathrm{~ms}$ times, though may be of up to 2 seconds for entirely unexpected and unplanned events (Lerner 1993). However, given the predicable nature of R/C control, a value of $250 \mathrm{~ms}$ will be assumed here (McCormick 1970). It should be noted the human operator can learn to predict instead of reacting to the motion of the aircraft. The use of "feed-forward" predictive control has not been addressed.

$\tau_{\mathrm{a} / \mathrm{c}}=$ Response Lag of the Airframe Avionics. This term is dominated by airframe avionics response rates (i.e. servos and flight surfaces). For the size of vehicle being considered here (i.e. equivalent to high-end $\mathrm{R} / \mathrm{C}$ aircraft) the dynamic response of the servos are very fast, typically on the order of about $20 \mathrm{~Hz}$, for a typical lag time of about $5 \mathrm{~ms}$ (Barnard 2007).

$\tau_{\text {comm }}=$ Communication Lag. This a combination of processing delays in the hardware, plus the physics involved in RF signal transmission (i.e. speed of light propagation) in both the send and receive directions. The magnitude of this total delay varies considerably depending on the manual pilot system used. For the case of a Manual Pilot (1) standing by the runway, or a Virtual Pilot sitting at a local GCS (2), the major source would be delays in the video/data feeds, perhaps due to hardware limitations in the RF link. The RF signal transmission path itself is insignificant (i.e. certainly less than $2 \mathrm{~km}$ ), resulting in total transmission delays of under 6.7 microseconds which may be ignored for purposes of our estimates here. The situation changes when attempting to teleoperate the UAV from a remote GCS as in (3). In this case, the communication lags could become very significant. This is particularly true if the link makes use of communication satellites. Turn-around delays of at least $500 \mathrm{~ms}$ and as much as 7 seconds are noted by some UAV researchers, especially if commercial geostationary types are used (Clough 2005). If a terrestrial feed is used (e.g. through an internet connection - horizontal path from the local GCS/receiving station to a remote GCS as shown) the channel delays would be dictated by the overall capacity of the network connection. The speed of the "weakest link" would determine the maximum throughput. This is likely to be the first link, from the local GCS which will typically be in a remote location and most likely away from high capacity hard-wired communication cables. In this case a wireless internet link to a nearby community or repeater tower may impose serious restrictions on the maximum data rate, possibly as low as $56 \mathrm{kbit} / \mathrm{sec}$. This may be adequate for attitude/control data but could severely limit the quality and frame rate of the video signal provided to the tele-operator.

$\tau_{\mathrm{gcs}}=$ Delays at the GCS due to software or hardware lags. This is not as great a concern now as it was over a decade ago. For example, most current laptop PCs are capable of running graphics-intensive software (i.e. games or flight simulators) while maintaining an animation frame rate well above the "flicker limit" of $25 \mathrm{~Hz}$. Frame-rates of $60-75 \mathrm{~Hz}$ are now the norm. To be prudent we will assume $25 \mathrm{~Hz}$ worst case here.

By assuming reasonable values for each delay term, a typical overall control delay for each of the three manual control scenarios may be calculated:

(1) Manual Pilot: $\tau_{\text {delay }}=\tau_{\text {pilot }}+\tau_{\mathrm{a} / \mathrm{c}}=255 \mathrm{~ms}$ 
(2) Local GCS: $\tau_{\text {delay }}=\tau_{\text {pilot }}+\tau_{\mathrm{a} / \mathrm{c}}+\tau_{\mathrm{gcs}}=359 \mathrm{~ms}$

(3) Remote GCS: $\tau_{\text {delay }}=\tau_{\text {pilot }}+\tau_{\mathrm{a} / \mathrm{c}}+\tau_{\text {comm }}+\tau_{\text {gcs }}=859$ ms (best-case) to 7.36 sec (worst-case)

\subsection{Effect of Airframe Dynamics}

Stable control of the UAV can only be assured if the overall speed of the controller (i.e. Manual Pilot including delays) is faster than the airframe. As a rule of thumb, it is desirable for the controller to be several times faster than the plant (i.e. airframe) under control, ideally 10 times faster although 5 times is acceptable (Levine 1996). Therefore for the local Manual Pilot (Case 1) we can estimate that the aircraft being controlled should have a minimum time constant of around $1.3 \mathrm{sec}$. The corresponding "controllable" airframe is slightly slower $(1.8 \mathrm{sec})$ for the Local GCS (Case 2), but quite a bit slower $(4.3 \mathrm{sec})$ for the Remote GCS (Case 3$)$ even for the bestcase communication scenario.

This analysis confirms what was observed during operations of the Aerosonde UAV and the GiantStik while under Manual Pilot control. Landing speeds (and dynamics) are relatively benign for the GiantStik. It lands with full flaps at about $8 \mathrm{~m} / \mathrm{s}(\sim 29 \mathrm{~km} / \mathrm{hr})$ with the engine still operating. The overall airframe response time in roll in good weather is something like 1.5-2.0 seconds. Therefore while fast, the GiantStik should still be within the control ability of most intermediate R/C pilots. In contrast, the Aerosonde lands typically at $18 \mathrm{~m} / \mathrm{s}(\sim 65 \mathrm{~km} / \mathrm{hr})$ without engine power. Its longitudinal (roll) axis time constant is estimated to be 0.75-1.0 seconds. This is below the range where a typical human operator can maintain control, and is why highly-skilled R/C pilots are needed for the Aerosonde EP role.

The combination of a fast airframe and excessive control delays may make it fundamentally impossible to safely control the small UAV under manual control, and result in pilot-induced-oscillations (McGuer 1995). During Aerosonde UAV trials, our EP noted a small lag (about $0.25 \mathrm{sec}$ ) when moving the Aerosonde flight surfaces using a standard R/C console when these control inputs were processed and transmitted through the Piccolo GCS. He noted that this lag was not present when flying his own normal highperformance R/C aircraft using direct R/C control (Trickett 2007). The sensitivity of the Aerosonde UAV, especially in roll, was always a cause for concern. The additional lag identified by the EP may have been a major contributor in the crash of an Aerosonde UAV (AC171) on 8 June 2008 on Bell Island, Newfoundland, Canada. If we compare the roll rate of the Aerosonde with the control lag of an EP whose commands must pass through a GCS (i.e. Case 2) that imposes an additional $0.25 \mathrm{sec}$ delay, we see that the safe control of the Aerosonde under manual control is questionable, especially at critical times such as when flying very close to the ground.

\subsection{VIRTUAL REALITY LANDING EXPERIMENTS}

A Virtual Pilot view (i.e. FPV) equivalent to a manned aircraft cockpit view) is hypothesized to be one way where the controllability of small UAVs may be improved during the most crucial portions of a mission - the takeoff and landing of the aircraft. This is a common technique used with larger military UAVs such as the Predator, which has become possible in smaller vehicles due to availability of miniaturized VR equipment at reasonable cost (DJI 2013).

A series of experiments have been conducted to answer the question: "What form of virtual (manual) piloting is the best method, or the most appropriate for small UAVs?" Three different forms of UAV manual control were assessed:

1. Radio Control (RC) Mode - the current "default" method, whereby the UAV is flown by R/C methods using un-aided external third-person view of the aircraft.

2. Flight Simulation (FS) Mode - A fixed forward camera view along the aircraft centerline, providing a First-Person View (FPV), shown to the pilot on a fixed screen, in a manner similar to a flight simulator.

3. Immersive (VR) Mode - An immersive view using VR Goggles, providing a FPV binocular video image on a set of tiny LCD screens directly in front of both eyes of the pilot. These goggles also featured 2-axis tilt sensors on the "forehead" of the goggle housing, providing a head-tracking ability. This allowed the VR pilots to turn his head and pan/tilt the camera on the aircraft, giving the illusion of being on the aircraft.

\subsection{Landing Experiment Design}


The experiment focused on the Landing Phase, as illustrated in Error! Reference source not found., which was used to assess maneuver accuracy while using different forms of manual control. As in manned aircraft, the primary objective is to land the UAV on the centerline of the runway, preferably just past the near end of the runway. This allows room for a successful post-landing roll and deceleration without running off the far end of the runway. At the same time, the track should be straight down the center of the runway, to avoid violent lateral accelerations or sideways runway excursions.

The experiment used a Design of Experiments (DOE) factorial approach. This allows the use of a sparse matrix of test factor combinations while preserving the statistical validity of the results. This is useful when conducting real-world tests where running a full statistical set of all possible combinations would be too expensive, dangerous or impractical. The objective in the DOE method is to determine those factors which are the most significant to the response variables being studied. By using a randomized order of test runs, the effect of random factors beyond the researchers' control is minimized and appears as "noise" in the statistical analysis.

$<$ figure 3 here $>$

\subsubsection{Independent Variables}

The following factors were studied in this experiment:

A = Form of Manual Piloting:

Radio Controlled (RC) Mode

Flight Simulator (FS) Mode

Immersive (VR) Mode

$\mathrm{B}=$ Skill Level of Pilot

Veteran $(10+$ years' experience)

Novice ( $<2$ years' experience)

$\mathrm{C}=$ Wind Conditions

Calm $(<10 \mathrm{~km} / \mathrm{hr})$

Windy $(>30 \mathrm{~km} / \mathrm{hr})$

\subsubsection{Response Variables}

To assess the quality of each landing, the following Response Variables were used:

$\mathrm{X}=$ Touchdown point along length of runway.

$\mathrm{Y}=$ Maximum deviation from runway centerline. During the experiment it was noted this was generally the touch-down point, as pilots generally corrected quickly to the centerline once landed.

\subsubsection{Total Number of Test Cases (Landings)}

Two repeats of each landing combination were used, which with the factor combinations listed yields a total of 24 landings, with 12 performed by each pilot. Using proper DOE factorial technique these should be done in a completely random order. However, given the nature of the environmental factor (i.e. Factor C, Winds) this is not practical. For this reason, the experiment was divided into two sets of 12 landings on two days, such all of the Calm and Windy cases were flown on a single day.

\subsubsection{Flight Test Vehicle}

A large R/C aircraft, the Great Planes Giant BigStik (hereafter called the GiantStik) was used as the test vehicle, as shown with the author in Error! Reference source not found.. In 2010 when this experiment was first performed, this was the largest member of this class of traditional R/C aircraft, with a wingspan of $2 \mathrm{~m}$, and maximum gross weight of about $7 \mathrm{~kg}$. Originally, a gasoline-powered 
version of the GiantStik was planned, but was converted to electric power. This greatly reduced the vibration issues encountered during initial tests of the VR equipment, and provided a stable video image for the pilots to use.

$<$ figure 4 here $>$

\subsubsection{VR Equipment (2010)}

Error! Reference source not found. provides a schematic of the VR equipment setup used during the 2010 VR Landing experiment. The equipment may be divided into a set of Airborne and Ground Components.

$<$ figure 5 here $>$

\section{Airborne Components}

a) VR Dome - The onboard camera was mounted on a 2-axis turret inside a small 4" acrylic hemispheric dome assembly, which was mounted on top of the main wing as shown in Error! Reference source not found.

b) Azimuth Range Extender - the rotation range of the azimuth servo was increased to approximately $+/-90$ degrees by use of a Pulse Width Modulation (PWM) range-doubler. This was installed similar to a servo extension cable. This allowed the VR pilot to look over each wing tip, similar to onboard pilot practice.

$<$ figure 6 here $>$

The camera and turret were obtained as part of the X11 FPV VR Set from RC-Tech in Switzerland in 2007 (RC-Tech 2010). Analog video was provided by a small NTSC-format camera with a $2.4 \mathrm{GHz}$ analog transmitter integrated to the back of the camera. The power source was a 7.4V 2-cell Lithium-polymer battery installed in the cylindrical base of the VR Dome assembly. The camera and integrated transmitter provided a reasonably clear image to a maximum range of about $1 \mathrm{~km}$, which was adequate for the landing experiment. The use of an analog $2.4 \mathrm{GHz}$ video link meant $2.4 \mathrm{GHz} / \mathrm{C}$ control could not be used, due to severe interference at the video receiver. For this reason the GiantStik used $72 \mathrm{MHz} F M \mathrm{R} / \mathrm{C}$ control. The two-axis turret permitted head-tracking by the camera, using two auxiliary channels of the aircraft $\mathrm{R} / \mathrm{C}$ receiver. The input to these servos are generated by the tilt sensors in the VR goggles detailed in the next section.

\section{Ground Components}

a) 2.4 GHz AV Receiver - The receive station for the video signal was a small $2.4 \mathrm{GHz}$ analog receiver, using a 4"x4" patch antenna. During the experiment, the aircraft was tracked manually by pointing the face of the patch antenna at the vehicle. This permitted clear video during most of the circuit used during the flights.

b) Video Splitter - A video-splitter was used so that the video feed could be sent to both the VR Goggles and a video capture card on a laptop.

c) Video Capture Card and Laptop - At the laptop, a PCMCIA card-bus video capture card was used to display and record video. The laptop LCD display was also used as the fixed view for the FS mode. Unfortunately, the ergonomics of this method were not ideal, as the original concept of a sit-down pilot with joystick control could not be implemented in time. Instead, the pilot looked at the fixed FS view while still using the R/C transmitter, requiring him to twist his body away from the flight line.

d) VR goggles - For VR mode, the test pilot wore a pair of goggles, as demonstrated in Error! Reference source not found.. Once comfortable and adjusted to this view, the 2-axis head tracking was activated using the FM transmitter "trainer switch". The VR setup was configured to use auxiliary channels 7 and 8 on a Futaba 9CAP $72 \mathrm{MHz}$ FM transmitter in "FUNC" mode. In this mode channels 1-6 are used for aircraft control, while channels 7 and 8 obtain their controls input through the VR goggle tilt sensors. These inputs are interfaced through the trainer port at the back of the transmitter. Assuming the tilt sensor was calibrated correctly, it tracked the pilot's head, giving the illusion of being in the cockpit of the GiantStik.

$<$ figure 7 here $>$

\section{Other Recording Instruments}


In addition to the laptop computer which recorded video from the VR camera, two tripod-mounted HD video cameras were used to record the landings from a side-runway and end-runway view. While the original intent was to use this video to measure the touchdown points of each landing, it was quicker and more straightforward to simply note the touchdown point for each landing, and mark the location quickly as soon as the aircraft had cleared, using sidewalk chalk. Accurate measurements were done once several landing test points were finished using a surveyors tape. During the experiment, the direction and magnitude of the wind speed was noted, making use of a mast-mounted anemometer on the mobile GCS.

\subsection{VR Experiment}

The VR experiment was conducted twice, once in 2010 and repeated in 2013.

\subsubsection{Test Site}

The 2010 experiment was conducted at the abandoned U.S. Air Base at Argentia, Newfoundland. Although much of the original runways and taxiways have deteriorated over the decades, there are still substantial areas adequate for small UAV testing. One such area, formerly a taxiway for strategic bombers, was used as the test site as shown in Error! Reference source not found.. The locations of the mobile GCS, test pilots and video recording cameras are noted. An $80 \mathrm{~m}$ x $8 \mathrm{~m}$ wide runway was established as shown, using high-visibility green paint. The centerline of the marked runway corresponded to the original centerline of the taxiway, which was still visible. The large green target in the center was drawn as the aiming point for the pilots. The pilots were located approximately $11-12 \mathrm{~m}$ away from the centerline of the make-shift runway.

$<$ figure 8 here $>$

\subsubsection{The Pilots of the 2010 Experiment}

For the 2010 experiment, two pilots were recruited from the RAVEN ${ }^{4}$ team:

a) Veteran Pilot - A German graduate student who spent 2010-2011 flying with Project RAVEN as the primary manual pilot. This pilot had approximate 10 years of experience flying R/C aircraft (mostly electric types) in Europe. He was also very familiar (and enthusiastic) about the use of VR flying methods, having tried it on several occasions in Germany.

b) Novice Pilot - One of the local graduate students who joined Project RAVEN in 2009. A recent flyer, he had achieved his "wings" earlier during the 2010 flying season. He was very comfortable flying the electric GiantStik and thus was an ideal "Novice" flyer candidate.

\subsubsection{Experimental Results}

The experiment was run over two days, August 25-26, 2010. Originally, it was hoped to run a blend of windy and calm conditions on each day, since this was a factor in the experiment and thus should have been randomized. However, as is usual for Newfoundland, the weather did not cooperate. Instead, the runs were divided into two blocks, one for each day. The Windy cases were done on Day 1 , with winds varying from $15-18 \mathrm{kts}$ (i.e. $31 \mathrm{~km} / \mathrm{hr}$ average), from the South-East (SE), approximately 45 degree to the right of the runway. This tended to push the aircraft off course to the left. The Calm Day runs were conducted on Day 2. The winds this time were $4-5 \mathrm{kts}(8.5 \mathrm{~km} / \mathrm{hr}$ average) for the majority of the tests. However, as is normal for coastal Newfoundland, the winds did pick up later in the day, peaking at $9 \mathrm{kts}(17 \mathrm{~km} / \mathrm{hr})$ by the end of the tests. The winds were again from the SE, approximately 30 degrees to the right of the runway.

\subsubsection{Analysis of 2010 Results}

The results from the 2010 VR Landing experiment were analyzed using a statistical approach using the commercial software called Design Expert (Stat-Ease 2014). The basic method used is an Analysis of Variance (ANOVA) for each of the response variables. A

\footnotetext{
${ }^{4}$ Project RAVEN (Remote Aerial Vehicle for Environmental Monitoring) was a major research project at Memorial University active from 2005-2014 in the field of UAVs. The primary objective was to develop operational techniques and technologies to permit the use of UAVs to augment commercial Intelligence Surveillance Reconnaissance (ISR) missions, such as the manned aerial patrols conducted by aircraft off Canada's east coast. A secondary objective (RAVEN II) was to investigate sense-and-avoid technologies to allow routine commercial UAV operations within both controlled and uncontrolled airspace.
} 
detailed description of this method and its use in the analysis of Design of Experiment (DOE) results is beyond the scope of this paper. The reader is directed to many excellent textbooks (Montgomery 2001) and online resources on this subject (Lane 2014). Based on the results of this analysis, the significance (or insignificance) of each factor, or combination of factors were assessed. The 2010 results were documented in a paper presented at UVS Canada 2010 (Stevenson 2010). These results are summarized in the form of a scatter plot in Figure 9. The mocked-up runway described previous described is shown here as a green outline, with the target location at the origin $(0,0)$.

<figure 9 here $>$

Early in the analysis there was concern over a major blocking effect imposed on Factor C (winds) given that the tests were conducted on two separate days. In a true factorial experiment, the order of each factor should be randomized. Since we were unable to do this for Factor C (winds), it is difficult to determine whether winds or some other unknown factor may be influencing major changes in the results from Day 1 to Day 2. For example, the effect of the winds appeared to be opposite of what was expected. Indeed, the quality of many of the landings on the second day (Calm winds) were worse, especially in terms of centerline deviation. It is possible that some other factor, including psychological factors, could have played a negative role in the Day 2 results. If we were to assess the results objectively, we see that:

a) Response (X) Landing Distance - The results indicate that the addition of the FPV modes did not improve accuracy, at least for the windy day cases. For both pilots, the FS mode tended to make for more variable landing distances, especially in high winds. The performance in Calm winds improved. In VR mode, the performance of the veteran pilot became worse. For the Novice pilot, there was an improvement. This was particularly true on the second (calm) day of testing. Comments from the Novice pilot were favorable towards the VR mode, with the comment that he was getting more comfortable using the VR goggle mode by the end of the experiment. However, both pilots complained about the difficulty in seeing the green runway outline far enough away to begin a good approach.

b) Response (Y) Off-Centerline Distance - The results for the centerline deviation measurements (Y) show a similar trend as with the landing distance results - the FS mode resulted in worse overall results in high winds, whereas the VR mode partially restored performance, especially for the less experienced pilot. However, the centerline deviations on the windy day were surprisingly consistent, while the equivalent results on the calm day showed a wider variability and overall worse results. For the case of the VR goggle mode, the calm day centerline distance for the two Novice landings varied widely, although in this case the "best" result of the entire experiment was accomplished by the Novice pilot $(\mathrm{X}=+0.6 \mathrm{~m}, \mathrm{Y}=0 \mathrm{~m})$.

c) Problems with FlightSim (FS) Mode - Most of the tests were accomplished quickly and without serious problems, apart from problems with the FS mode on Day 2. The FS mode suffered from poor ergonomics during the experiment, and may have biased the results when the pilots used this mode. The need to twist the body to see a laptop LCD display in the back of vehicle (to provide a sunshield) was not ideal, especially while using an FM R/C transmitter with its long $(1.5 \mathrm{~m})$ antenna. The position of the antenna so close to a large metallic object (the vehicle) is also suspected of causing radio interference which resulted in one of the FS cases being aborted due to safety concerns.

\subsubsection{Summary of 2010 Experiment}

For the experienced R/C pilot the default RC mode was the method which he was most comfortable using, and seemed the most appropriate (accurate) method for landing small UAVs under manual control. The addition of VR technologies did not assist the experienced $\mathrm{R} / \mathrm{C}$ flier, and instead appeared to degrade landing accuracy.

In the case of the less-experienced flyer, the addition of VR technologies did provide some assistance, improving landing accuracy, especially in terms of centerline deviation (Y). However, the fixed Flight Simulator (FS) mode in general yielded worse performance. It is very likely that the poor ergonomics of the makeshift FS mode used during these experiments had a negative effect on these results.

It was hypothesized that the landing task would be easier in calm winds, and that VR methods would improve accuracy especially in the presence of a strong cross wind (e.g. permitting a more accurate line-up with the centerline). Higher winds did result in some variation from run to run but in general accuracy was as good, if not better, then on the calm day. However, the results may be masked by a strong blocking effect (i.e. perhaps someone was having a "better day" on Day 1?). Even tension within the team, evident at the end of the first day of testing, and schedule pressure on the second day could have been a significant source of bias. 
The choice of test site was also sub-standard. Throughout the experiment there were frequent comments by both pilots about the difficulty seeing the makeshift green runway outline. The pilots reported they were using the original yellow taxi-way centerline as their primary visual cue. This may have helped in line-up for the landing, thus impacting the centerline deviation (Y) response, but unfortunately provided no help in obtaining an accurate landing distance (X). The pilots reported they could only see the green runway markings during the final seconds of each landing. Thus, the choice of this test site likely hampered the assessment of the improvements to accuracy provided by the use of VR methods.

\subsection{VR Experiment at Bell Island}

Due to the inconclusive results in 2010, the experiment was repeated in November 2013. The test site was moved to the originally planned location at the Bell Island airfield (CCV4) as shown in Figure 10. The locations of the pilots, side and end cameras and a trailer used as the GCS are noted. The target point for the landings was between the numbers " 26 ", directly in front of the pilots. The runway is $66 \mathrm{ft}(20 \mathrm{~m})$ wide at this location. The pilot station was at the edge of the runway, about $10 \mathrm{~m}$ from the centerline

$<$ figure 10 here $>$

\subsubsection{Test Vehicles for 2013}

An electric-propulsion GiantStik was used again in 2013, although not the identical aircraft from the 2010 experiment, as this aircraft was unfortunately lost in a flight mishap in 2011. Two new electric-propulsion GiantStik aircraft were constructed (GBS\#10 and GBS\#11) to support the 2013 experiment. During initial flight testing to test the FPV equipment, GBS\#11 was lost at sea north of Argentia while investigating interference problems with the video link. The significance of this event will be discussed in Section 4.4. A third aircraft (GBS\#12) was constructed as a replacement, so that a second aircraft would always be available in case the primary vehicle was lost. This proved un-necessary and GBS\#10, shown in Error! Reference source not found., performed its function perfectly and survived.

$<$ figure 11 here $>$

\subsubsection{The Pilots of the 2013 Experiment}

For the 2013 Experiment, a new pair of pilots was recruited:

a) Veteran Pilot - the veteran pilot was the primary manual pilot for Project RAVEN since 2012. He had about 10 years flying experience flying $\mathrm{R} / \mathrm{C}$ aircraft at the time of the experiment, including one year experience using FPV equipment with his own personal R/C flying.

b) Novice Pilot - the novice pilot in 2013 was a staff engineer from Project RAVEN. He had been flying R/C aircraft for the previous two flying seasons, although most of this experience was on the smaller Ultra40 and electric "foamy" type aircraft. He appeared to be nervous about stepping up to fly the relatively large GiantStik, but quickly learned it shared much of the flight characteristics as the smaller Ultra40.

\subsubsection{Updated 2013 VR Equipment}

The state of the art of VR equipment has advanced significantly since the original VR1000-based system used in the 2010 experiment. The older VR1000-based equipment was replaced by updated First Person View (FPV) components, based on the EagleTree series of FPV products. Aimed at the high-end R/C hobby community, these FPV components are now borderline UAV avionics sets, including built-in GPS, On-Screen Displays (OSD), and a rudimentary autopilot-capability (Eagle Tree Systems 2013). For these experiments only the GPS and OSD features were used.

\section{Airborne Components}

a) VR Turret - The onboard camera was a NTSC format analog camera supplied in an integrated pan/tilt turret format. This was installed on the GiantStik using a custom built mount held to the top of the main wing using a rubber/plastic band (similar to the aluminum flashing band used in the 2010 experiment), as shown in Error! Reference source not found.. Suspected RF interference prompted a switch to the rubber/plastic material. 
$<$ figure 12 here $>$

b) EagleTree FPV Setup - The complete FPV system as installed on the aircraft consisted of the components shown in the annotated Error! Reference source not found. The new FPV system used a dedicated $5.8 \mathrm{GHz}$ high-power video transmitter (C). Initially the normal $5.8 \mathrm{GHz}$ antenna (B) was used, but this was switched to a special mushroom-shaped bi-polar style antenna (A) which had superior transmission range, especially when combined with a more powerful transmitter (i.e. at least $6 \mathrm{~km}$ when used with a $600 \mathrm{~mW}$ transmitter). For the electric-powered GiantStik application a power monitoring board (D) is used to monitor the battery and propulsion system health. The main on-screen display (OSD) board (E) is the heart of the airborne FPV equipment, and serves as both the signal processing and signal relay board for the other components. The video from the camera (F) is sent to the OSD board, which adds the Heads-Up-Display (HUD) elements, before sending this enhanced video image along to the transmitter. This includes the previously mentioned electrical system information and also the 2D tilt position status obtained from the tilt sensors $(\mathrm{H})$ which is used to drive an artificial horizon display. The GPS module $(\mathrm{G})$ provides the 3D position of the aircraft, which the OSD uses to calculate altitude, ground speed and the position of "home base" which is the saved location when the OSD was first turned on (i.e. the GCS location). The rectangular box (I) at top is a small solid-state recording device which is actually part of the Ground Components, and described in the next section.

$<$ figure 13 here>

\section{Ground Components}

a) VR Goggles - The 2013 VR experiment used a new set of VR goggles from "Fat Shark" (Fat Shark 2013). These goggles have a built-in receiver. The new headset also includes pan/tilt sensors, similar to those in the VR1000, but with much better accuracy and reliability. The modern FPV equipment used a solid-state data recorder (i.e. Component I in Figure 3-16) to record the FPV video, eliminating the need to use a video capture card. The new style of goggles used can be seen being worn by one of the pilots in Error! Reference source not found.

$<$ figure 14 here $>$

b) HUD Display (2013) - The FPV equipment featured a HUD display, using the sensors on the aircraft to measure GPS location and pan/tilt of the aircraft. A sample of the display provided to the VR pilots is shown in Error! Reference source not found.. As shown, the HUD provided the current aircraft position, ground speed (mi/hr) and altitude above ground ( $\mathrm{ft}$ ) in the form of "ladders" on the left and right sides respectively, as well as an artificial horizon. The items in the lower left and right corners provided the current power draw and total power consumed by the electrical propulsion system. Since we used 10,000 mAH of total battery power this display acted like a "fuel gauge" letting us know when the aircraft power was dropping too low (i.e. when total power consumed exceeded $8000 \mathrm{mAH}$ ). Even in cold weather (i.e. $1-4{ }^{\circ} \mathrm{C}$ ), we had flight endurances of between 20 and 25 minutes on a fully charged set of batteries.

$<$ figure 15 here $>$

c) Improved "FlightSim" Display - The 2013 experiment used a dedicated FPV LCD display for the FS mode tests, mounted on a tripod in front of the pilot, as shown in Figure 16. This eliminated the need for pilots to twist their bodies to view an LCD screen crammed into the back of a vehicle. In addition to improving the poor ergonomics encountered in 2010, this arrangement also eliminated the contradiction due to the pilot's aural (hearing) cues as the aircraft flew past when his back was turned away from the runway. The LCD screen also included a safety feature which normal TV or computer monitors do not have. If the video signal strength (and thus quality) drops below some threshold, normal LCD screens typically go blank with a blue screen. The modified FPV display is an analog device, and will continue to show the degraded video. The VR goggle displays also behaved in this analog manner. Even a scratchy black-and-white display is better than nothing. During the experiment, such video drop-outs were of limited duration (1-2 seconds) and only when the aircraft was turned away from the receive station and when range exceeded $1 \mathrm{~km}$. The stability of the display during final approach to landing were near-perfect. The updated FPV LCD display allowed a much better assessment of the effectiveness of the FS mode during the 2013 experiment.

$<$ figure 16 here $>$ 


\subsubsection{Experimental Results}

The 2013 experiment was ran on November 29, 2013. The winds were down the runway (i.e. almost no cross wind) at 5-7 knots (9-13 $\mathrm{km} / \mathrm{hr})$. Conditions were sunny with a few clouds but quite cold $\left(\sim 2{ }^{\circ} \mathrm{C}\right)$. The test cases ran in the morning were deemed to be "Calm Day" conditions. The results showed a marked improvement in overall pilot performance versus the 2010 results. The effect of running the experiment on a proper runway, with aviation-grade markings was clear. Both pilots reported it was very easy to see the runway threshold, centerline and the numbers from a long distance, allowing for improved line-ups and precision landings.

Similar to the 2010 results, the 2013 results show a gradual improvement as the tests were conducted, indicating a "training factor" may be involved. The one disappointment though was in the VR mode test cases by the Novice pilot. He expressed some discomfort with the VR mode, in contrast to the RC and FS modes. This led to loss of orientation on several occasions, resulting in some erratic flying and difficulty in performing safe landing approaches. In both VR landing attempts, the situation deteriorated to the point were safety for the GCS crew was a concern, and the other pilot had to take over emergency control.

Following the morning tests, and facing deteriorating team morale and weather, it was decided to perform a series of "demonstration" runs. The (first) author stepped in to be an alternative Novice pilot. Only four cases were ran before weather conditions forced a stop to the experiment. Both pilots expressed optimism about the quality of the video feed, and also the ease of flying well coordinated approaches. The VR mode was not disorienting for either of us. The accuracy of the approaches, especially in terms of centerline deviation, is pretty clear. One of the author's approaches went quite long, similar to full-sized aircraft "floating" behavior, but landed on the centerline of the runway. Note that the precision demonstrated in this long landing would have been impossible using a normal $\mathrm{R} / \mathrm{C}$ third-person view given the viewing angle, slight slope of the runway and extreme range at touch down.

\subsubsection{Analysis of 2013 Results}

The results of the 2013 VR experiment were not analyzed using the ANOVA approach as in 2010, due to the lack of a full set of results for "windy" conditions. The switch in Novice pilot would also invalidate any statistical comparison. However, when the results are combined and presented in the form of a scatter plot, as shown in Error! Reference source not found., some trends can be observed. The outline of the end of runway 26 is shown as a green line. The target location $(0,0)$ was in between the centers of the " 2 " and " 6 " on the runway.

<figure 17 here>

The accuracy of the landings, now constrained by a $66 \mathrm{ft}(20 \mathrm{~m})$ wide runway, have improved. The centerline distance, apart from two of the FS mode cases, are quite good. Landing distance is very good too, but generally "long" when FS mode is used. The accuracy of the VR mode landings were very good. The ease of lining up a good landing, experienced personally by this author, was greatly increased when the immersive 3D VR mode was used. But the poor performance of the first Novice pilot while using the VR modes was a concern. It became evident that while the VR mode assisted the author and veteran pilot, both who have flown flight simulators extensively since adolescence, to a person untrained in manned aircraft flight the VR mode does not appear to provide the same advantage. The Novice pilot first learned to fly using R/C mode, and this appears to be the method he is most comfortable with. This was a result those of us involved in aviation had not considered. Learning to fly $\mathrm{R} / \mathrm{C}$ aircraft normally requires combatting the third person disorientation effects caused by control reversal. The FPV mode is one way of skipping this problem altogether, but only seems to help someone already trained in manned aviation practices.

Following the 2013 experiment, the video footage from both series of experiments were re-examined. The measurements of landing distance $(\mathrm{X})$ and centerline deviation $(\mathrm{Y})$ do not tell the complete story. It was noted that when flying in RC mode, the aircraft turns and altitude holding were not as accurate or smooth as with either of the FPV modes. When flying FPV, the pilot appears to naturally start to fly like a full-size aircraft. Turns are gentler with bank angles more typical of manned aircraft. Altitude, especially with the addition of HUD instruments, is held within 50 feet. The size of the circuits are also much bigger in FPV mode, with the pilot flying downrange quite some distance before turning onto final approach. This last observation has significant repercussions as elaborated on in the next section.

\subsection{Significance of the Loss of GSB\#11}

The loss of GBS\#11 during initial FPV equipment shakedown, while not a planned event, is an important result of the 2013 VR experiment. It was flown beyond the range of the FPV video transmitter resulting in a loss of video signal, and was too far away to allow recovery using normal R/C means. This illustrates one of the dangers of using FPV mode - pilots tend to fly much higher and 
further than normal R/C flying, possibly in an attempt to emulate manned aviation practice, to the point where FPV becomes the only viable means of manual remote control. The exceptionally large size of the runways at Argentia (i.e. 200 foot wide runways) only served to exacerbate this tendency.

Without a reliable BVLOS manual control link, the use of R/C methods alone at the extended ranges encouraged by the use of FPV may render the small UAV uncontrollable. It is for this reason that both the MAAC and AMA have set strict guidelines on the use of FPV techniques. In general, FPV can only be used within unassisted visual range and always with the presence of dedicated spotter who is also a second pilot ready to assume normal R/C control at a moment's notice, should the FPV pilot become disorientated or the FPV equipment fail (MAAC 2012). This was the safety procedure we followed in both the 2010 and 2013 experiments. Transport Canada also cautions the UAV operator to not assume that FPV technology alone can provide an equivalent situational awareness at BVLOS ranges, as the "sense and avoid" function of a manned aircraft pilot (Transport Canada 2014).

\subsection{SUMMARY OF RESULTS}

The experiments described in this paper suffered from low sample size and a certain lack of randomness, and therefore any statistical results should be viewed with some caution. However, the experience and the observations noted into the use of novel VR control methods are important, especially the last results gathered in the 2013 experiment. When the results from both series of VR experiments are considered together there are a number of important observations may be drawn:

1. The use of a real runway, using aviation grade markings, results in a significant improvement in VR mode landing accuracy, but has almost no effect on $\mathrm{R} / \mathrm{C}$ mode.

2. For someone "entrenched" in the use of R/C techniques for flying small UAVs, the addition of VR methods may initially hinder landing accuracy.

3. The VR method appears to be a promising method, but only if used by pilots already familiar with the basics of good airmanship.

4. There appears to be a strong training effect involved in the use of VR methods for UAV control. During both experiments, there was evidence that pilot performance was improving gradually as the test progressed. To someone already trained in the use of FPV methods, such as the second Veteran pilot, this effect was strong.

5. The fixed-view FS mode, while being easier to implement (i.e. not requiring the tilt sensor or head tracking equipment) appears to be less accurate then the VR mode.

6. It is possible, especially when the second (2013) set of results are examined, that there may be a fear factor involved when using the FS method next to an active runway. Forcing yourself to look at a small FPV screen when you could hear the aircraft approaching was difficult. The natural tendency for most $\mathrm{R} / \mathrm{C}$ pilots is to avoid hitting yourself with your own aircraft! Most R/C pilots tend to err on the side of safety, and land away from the pilot position. The FS mode results from 2013 show this effect.

7. The addition of a HUD display improves the quality of the landing approach and with practice, encourages the use of proper glideslopes, altitudes, landing speeds and flared landings.

8. When flying in FPV mode, pilots have a tendency to fly higher and further than normal R/C flying. It therefore becomes crucial that sufficient video feed signal strength (i.e. range) is provided to avoid sudden video signal drop-outs.

9. The loss of a test aircraft during FPV equipment shakedown testing in 2013 demonstrated a key weakness of the FPV mode. When under FPV manual mode, the manual pilot will tend to fly well beyond normal visual range, but still be within the electronic line of site (eLOS) range of the $\mathrm{R} / \mathrm{C}$ radio link. A failure of the video link at this point renders manual control of the UAV impossible, without some other form of backup control model.

\subsection{RECOMMENDATIONS FOR FUTURE WORK}

The results from the VR landing experiments documented in this paper represent pioneering efforts to determine a better way to manually control a small UAV, especially during the critical landing stage. The use of FPV methods has shown some promise in simplifying this task and making it safer. However, the choice between a fixed-forward (FS mode) or immersive 3D (VR mode) remains unclear. Further work is needed to establish a firm statistical basis for making this choice. It is recommended as a follow-on 
research activity that a more focused series of landing trials be conducted with many more pilot candidates. Ideally, these pilots should possess some minimum R/C and FPV training before the start of the experiment. Multiple landings (i.e. 10+) in each of the two FPV methods should be conducted by each pilot candidate to assess the accuracy of each mode on a more statistical basis. Testing of other critical flight tasks, especially takeoffs and climb to a stable flight circuit for AP control pass-off should also be considered.

\subsection{ACKNOWLEDGMENTS}

This research was supported financially through the National Sciences and Research Council of Canada (NSERC) and the Atlantic Canada Opportunity Agency (ACOA).

\subsection{REFERENCES}

3DRobotics. 2013. APM: Plane, Open Source Autopilot, Version 2.74. July 15. www.ardupilot.com.

ASDNews. 2012. "Predator B Demos Automatic Takeoff and Landing Capability." Aerospace and Defense News. Sept 18. http://www.asdnews.com/news-45001/Predator_B_Demos_Automatic_Takeoff_and_Landing_Capability.htm.

Barnard, Joseph. 2007. "Small UAV Command, Control and Communication Issues." Barnard Microsystems Limited. http://www.barnardmicrosystems.com/media/presentations/IET_UAV_C2_Barnard_DEC_2007.pdf.

Bento, Maria de Fatima. 2008. "Unmanned Aerial Vehicles: An Overview." Inside GNSS, Jan/Feb.

Clough, Bruce T. 2005. "Unmanned Aerial Vehicles: Autonomous Control Challenges, a Researcher's Perspective." Journal of Aerospace Computing, Information and Communication, Volume 2, Issue 8 327-347.

Contarino, Mark. December 5, 2009. All Weather Sense and Avoid System for UASs. Report to Office of Naval Research, R3 Engineering, Scire Consultants.

DJI. 2013. FPV Flight - DJI Wiki. Jan 23. Accessed May 01, 2015. http://wiki.dji.com/en/index.php/FPV_Flight.

Eagle Tree Systems. 2013. Guardian and OSD FPV. https://www.eagletreesystems.com.

EC. 2009. "HEARING ON LIGHT UNMANNED AIRCRAFT SYSTEMS (UAS)." European Commission (EC), Directorate F - Air Transport. October 08. http://ec.europa.eu/transport/modes/air/doc/2009_10_08_hearing_uas.pdf.

Ellis, K. 2006. Investigation of Emerging Technologies and Regulations for UÄV 'Sense and Avoid' Capability. National Research Council Institute for Aerospace Research, Report LTR-FR-258.

FAA. 2008. "Interim Operational Approval Guidance 08-01: Unmanned Aircraft Systems Operations in the U.S. National Airspace System." Federal Aviation Administration. March 13.

http://www.faa.gov/about/office_org/headquarters_offices/ato/service_units/systemops/aaim/organizations/uas/coa/faq/media /uas_guidance08-01.pdf.

FAA. 2015. Operation and Certification of Small Unmanned Aircraft Systems. FAA-2015-0150; Notice No. 15-01, Washington, D.C.: Federal Aviation Administration, U.S. Department of Transportation.

Fat Shark . 2013. Attitude V2 FPV Goggle with Trinity Head Tracking, User Manual, Revision B, 12/23/2013. Fat Shark RC Vision Systems .

Federal Aviation Administration (FAA). 2010. Automatic Dependent Surveillance-Broadcast (ADS-B) Out Performance Requirements to Support Air Traffic Control (ATC) Service, 14 CFR Part 91. Department of Transportation.

Haven, Kendall. 2011. "Controlling the Public Perception of Unmanned Systems and Robotics." AUVSI, Volume 29 No.8, August.

Hodges, Jim. 2009. "Computer co-pilots: 'Smarter' UAVs Could Help Avoid Human Error During Landings." Defense News. Sept 1. http://www.defensenews.com/print/article/20090901/C4ISR02/909010307/Computer-co-pilots.

Hungarian State News Agency. 13 May 2006. "2 Killed At Airshow. RC Plane Responsible." Budapest, Hungary.

ICAO. 2013. 2013 Safety Report. Montreal: International Civil Aviation Organization (ICAO). Accessed July $22,2014$. http://www.icao.int/safety/State\%20of\%20Global\%20Aviation\%20Safety/ICAO_SGAS_book_EN_SEPT2013_final_web.pd f.

ICAO. 2011. "Unmanned Aircraft Systems (UAS), Circular 328, AN/190, ." International Civil Aviation Organization.

King., D.W., A. Bertapelle, and C. Moses. September, 2005. "UAV Failure Rate Criteria for Equivalent Level of Safety,." International Helicopter Safety Symposium. Montreal: American Helicopter Society International.

Kirkby, Bob. November 2006. "Sharing the Air from a General Aviation Perspective." UVS Canada 5th Annual Conference . Montebello, Quebec.

Lane, David M. 2014. Analysis of Variance (ANOVA) - Introduction. August 21. http://onlinestatbook.com/2/analysis_of_variance/intro.html.

Lerner, N.D. 1993. "Brake Perception-Reaction Times of Older and Younger Drivers." Proceedings of the Human Factors and Ergonomics Society 37th Annual Meeting. Santa Monica, CA. 206-210.

Levine, William S. 1996. The Control Handbook. Boca Raton, FL: CRC Press LLC. 
MAAC. 2012. "FPV Guidelines." Model Aeronautics Association of Canada. http://www.maac.ca/docs/2012/maac_fpv_guidelines.pdf.

MacDonald, A. F., and I. L. Peppler. 2000. From the Ground Up, Millennium Edition. Ottawa, Ontario, Canada: Aviation Publishers Co. Limited.

McCalmont, J., J. Utt, M. Deschenes, M. Taylor, R. Sanderson, J. Montgomery, R.S. Johnson, and D. McDermott. 2007. "Sense and Avoid Technology for Unmanned Aircraft Systems." Automatic Target Recognition XVII, Vol. 6566. Proceedings of SPIE.

McCormick, Ernest J. 1970. Human Factors Engineering, 3rd Ed. New York: McGraw-Hill.

McGuer, Duane T. 1995. Pilot-Induced Oscillations and Human Dynamic Behavior. Contractor Report 4683, NASA.

MicroAir . June 2009. "T2000UAV-S Transponder Installation and User Manual. Queensland, Australia: Microair Avionics Pty. Ltd. . Model Aeronautics Association of Canada (MAAC). 2014. "R/C Flying Field Specifications." MAAC Guidelines, January 23.

Mohammed S. Santina, Allen R. Stubberud, Gene H. Hostetter. 1996. "Chapter 16: Sample-Rate Selection." In The Control Handbook, by William S. Levine, 313-317. Boca Raton, FL: CRC Press LLC.

Montgomery, Douglas C. 2001. Design and Analysis of Experiments (5th ed.). New York: Wiley.

Murfin, Tony. 2013. FAA Roadmap 2013. GNSS Aerospace.

NATO Naval Armaments Group. 2007. Sense and Avoid Requirements for Unmanned Aerial Vehicle Systems Operating in NonSegregated Airspace, PFP(NNAG-JCGUAV)WP(2006)0002-REV2. Joint Capability Group on Unmanned Aerial Vehicles.

NTSB/AAR-87/07. 1986. Collision of Aeronaves de Mexico, S.A. McDonnell Douglas DC-9-32, XA-JED and Piper PA-28-181, N489lF, Cerritos, California. National Transport Safety Board (NTSB) Accident Report.

RC-Tech. 2010. X11 FPV Set. http://www.rc-tech.ch.

Smith, G.R., Sr., and G.R., Jr. Smith. 2000. "A Virtual Reality Flight Trainer for the UAV Remote Pilot." Proceedings of SPIE, Vol. 4021. The International Society for Optical Engineering (SPIE). 224-233 .

Stat-Ease. 2014. Design-Expert V8 Software for Design of Experiments (DOE). August 21. http://www.legacy.statease.com/dx8descr.html.

Statistics Canada. 2013. "Aircraft Movement Statistics: NAV CANADA Towers and Flight Service Stations (TP 141)." Statistics Canada. Dec. Accessed July 22, 2014. http:/www.statcan.gc.ca/pub/51-007-x/51-007-x2013012-eng.htm.

Statistics Canada (StatCan). 2014. "2011 Census Data ." Statistics Canada. May 13. Accessed July $22,2014$. http://www12.statcan.gc.ca/census-recensement/index-eng.cfm.

Stevenson, Jonathan. 2010. "Assessment of UAV Manual Pilot Techniques using a Design of Experiment Approach." UVS Canada 2010. Montreal, Canada: AUVSI Canada.

Transport Canada. 2014. Canadian Aviation Regulations, CAR 523-VLA-1. April 29. Accessed July $22,2014$. http://www.tc.gc.ca/eng/civilaviation/regserv/cars/part5-standards-523vla-1808.htm.

Transport Canada. 2014. Canadian Civil Aircraft Register. January. Accessed July 22, 2014. http://wwwapps2.tc.gc.ca/saf-secsur/2/ccarcs/aspscripts/en/menu.asp.

Transport Canada. 2014. "Review and Processing of an Application for a Special Flight Operations Certificate for the Operation off an Unmanned Air Viehicle (UAV) System." Staff Instruction (SI) No. 623-001. Nov 19. Accessed Dec 1, 2014. http://www.tc.gc.ca/eng/civilaviation/opssvs/managementservices-referencecentre-documents-600-623-001-972.htm.

Transport Canada. 2014. "TP15263 - Knowledge Requirements for Pilots of Unmanned Air Vehicle Systems (UAV) 25 kg or Less, Operating within Visual Line of Sight." Transport Canada. August. http://www.tc.gc.ca/eng/civilaviation/publications/page6557.html.

Transport Canada. 2010. Unmanned Air Vehicle (UAV). May 3. Accessed May 15 , 2014. http://www.tc.gc.ca/eng/civilaviation/standards/general-recavi-brochures-uav-2270.htm.

Trickett, Craig, interview by Jonathan Stevenson. 2007. Discussions of External Pilot Control Lags with Aerosonde GCS (October 16).

TSB Report A12C0053. 12 May 2012. Aviation Investigation Report: Midair Collision Piper PA-28R-200 Arrow C-GLAJ and Lake La-4-200 Buccaneer C-GFCH, St.Brieux, Saskatchewan. Transport Safety Board of Canada.

TSB. 2014. "Statistical Summary - Aviation Occurrences 2012." Transport Safety Board of Canada. March 19. Accessed July 22, 2014. http://www.tsb.gc.ca/eng/stats/aviation/2012/ss12.asp.

UAV Working Group. 2007. Unmanned Air Vehicle Working Group Final Report. Civil Aviation, Transport Canada.

Unmanned Dynamics. 2006. AeroSIM Aeronautical Simulation Blockset, Version 1.2. Hood River, OR: Unmanned Dynamics Inc.

Weibel, R. E., and R.J. Hansman. March 2005. Safety Considerations for Operation of Unmanned Aerial Vehicles in the National Airspace System. Cambridge, MA: MIT International Center for Air Transportation, Report No. ICAT-2005-1.

Williams, Kevin. 2004. A Summary of Unmanned Aircraft Accident/Incident Data: Human Factors Implications. Oklahoma City: Federal Aviation Administration. 
Figure 1: UAV Manual Pilot Control Situation

Figure 2: Sources of Control Delay during Manual Piloting

Figure 3: Diagram of Landing Task for VR Experiment

Figure 4: GiantStik Test Vehicle (2010)

Figure 5: VR Equipment Schematic (2010)

Figure 6: VR Dome Installation (2010)

Figure 7: VR1000 Goggles (2010)

Figure 8: Test Site at Argentia (2010)

Figure 9: Landing Positions, 2010 VR Experiment

Figure 10: Test Site at Bell Island (2013)

Figure 11: GiantStik\#10 Test Vehicle (2013)

Figure 12: Airborne FPV Installation (2013)

Figure 13: EagleTree FPV Components (2013)

Figure 14: FatShark VR Goggles (2013)

Figure 15: FPV Display with HUD (2013)

Figure 16: FPV LCD Display on Tripod (2013)

Figure 17: Landing Positions, 2013 VR Experiment 


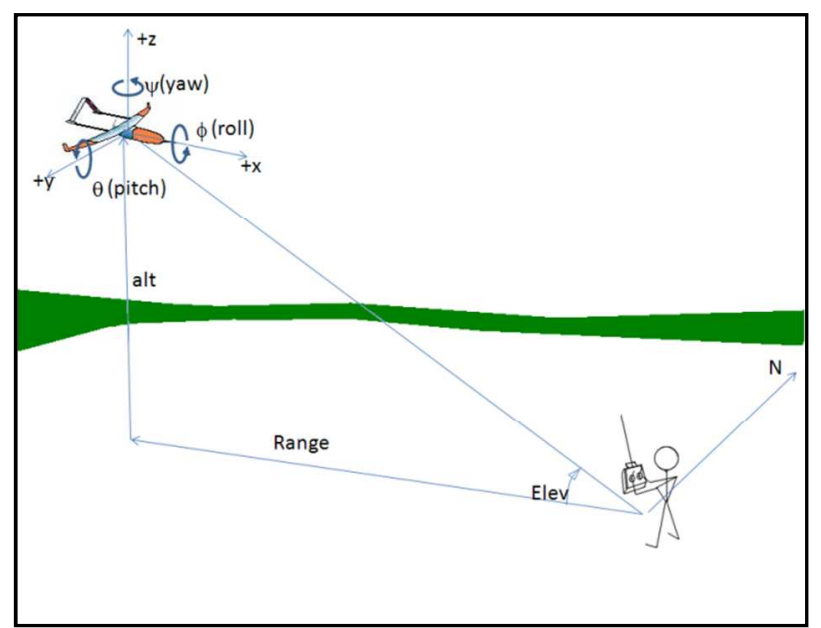

Figure 1: UAV Manual Pilot Control Situation 


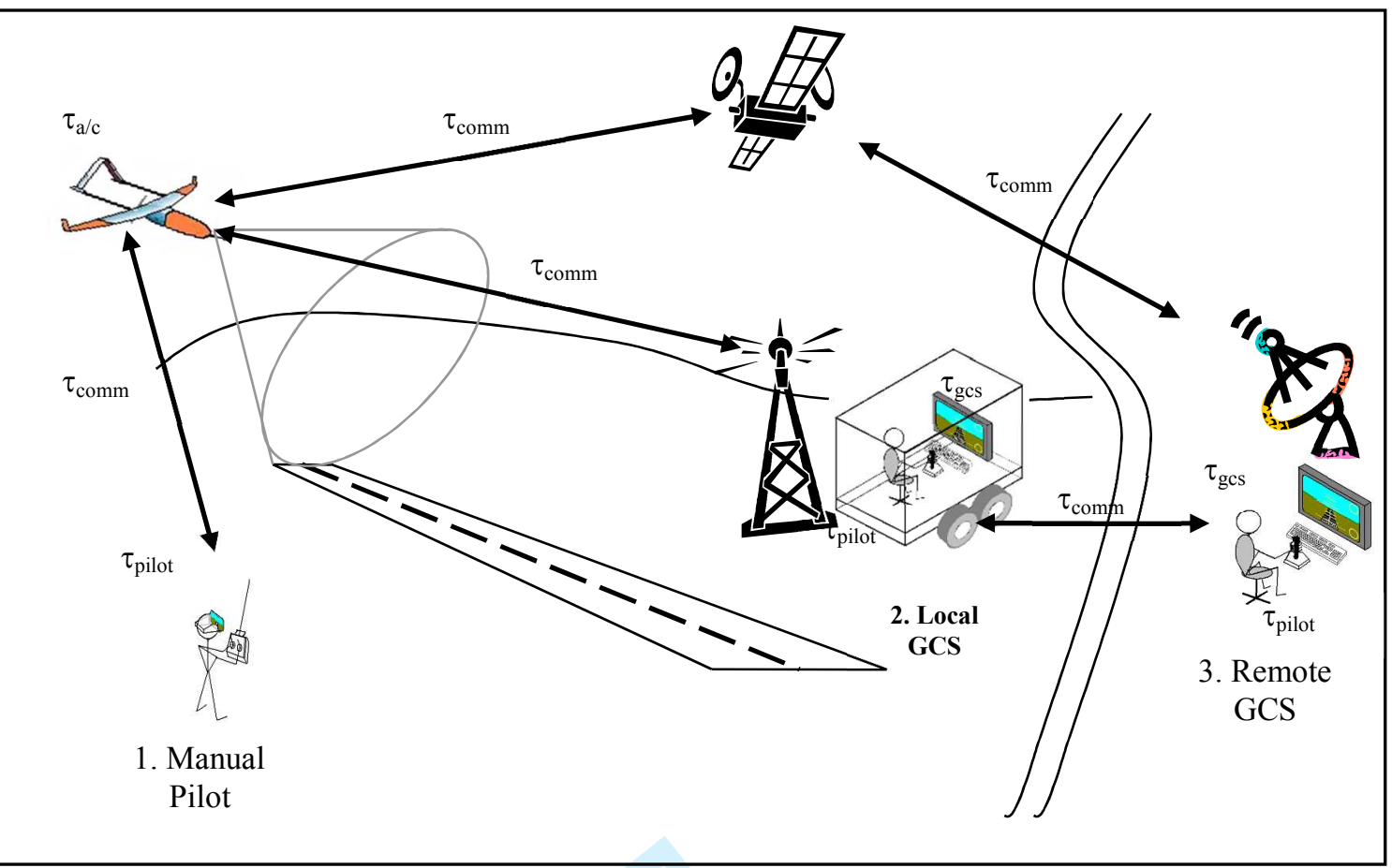

Figure 2: Sources of Control Delay during Manual Piloting 


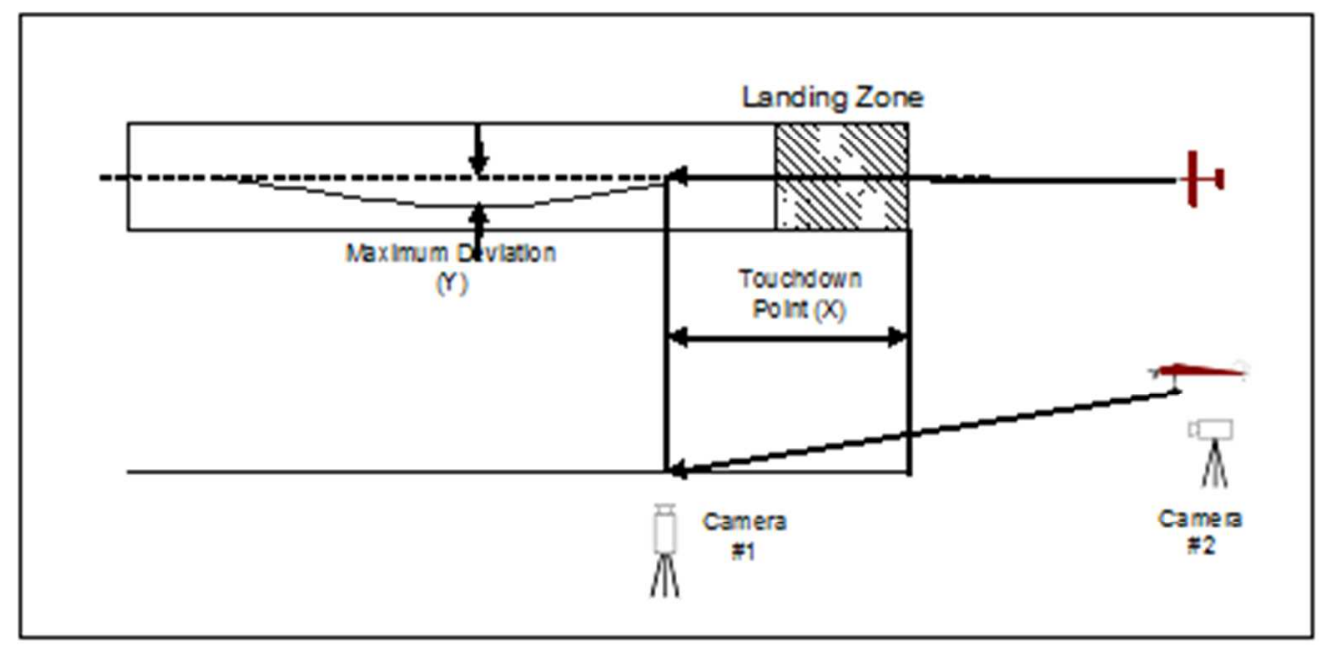

Figure 3: Diagram of Landing Task for VR Experiment 


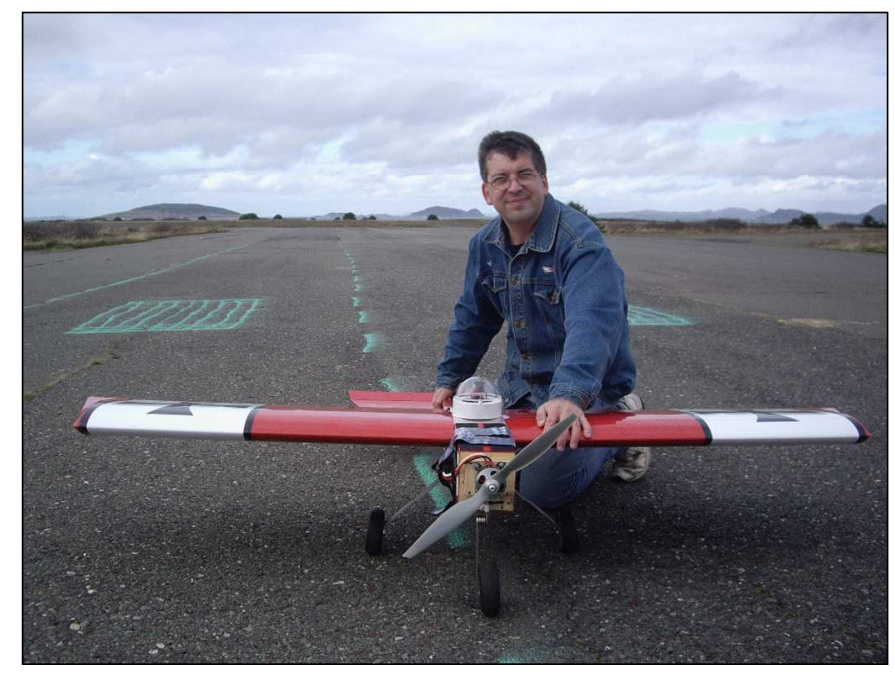

Figure 4: GiantStik Test Vehicle (2010) 


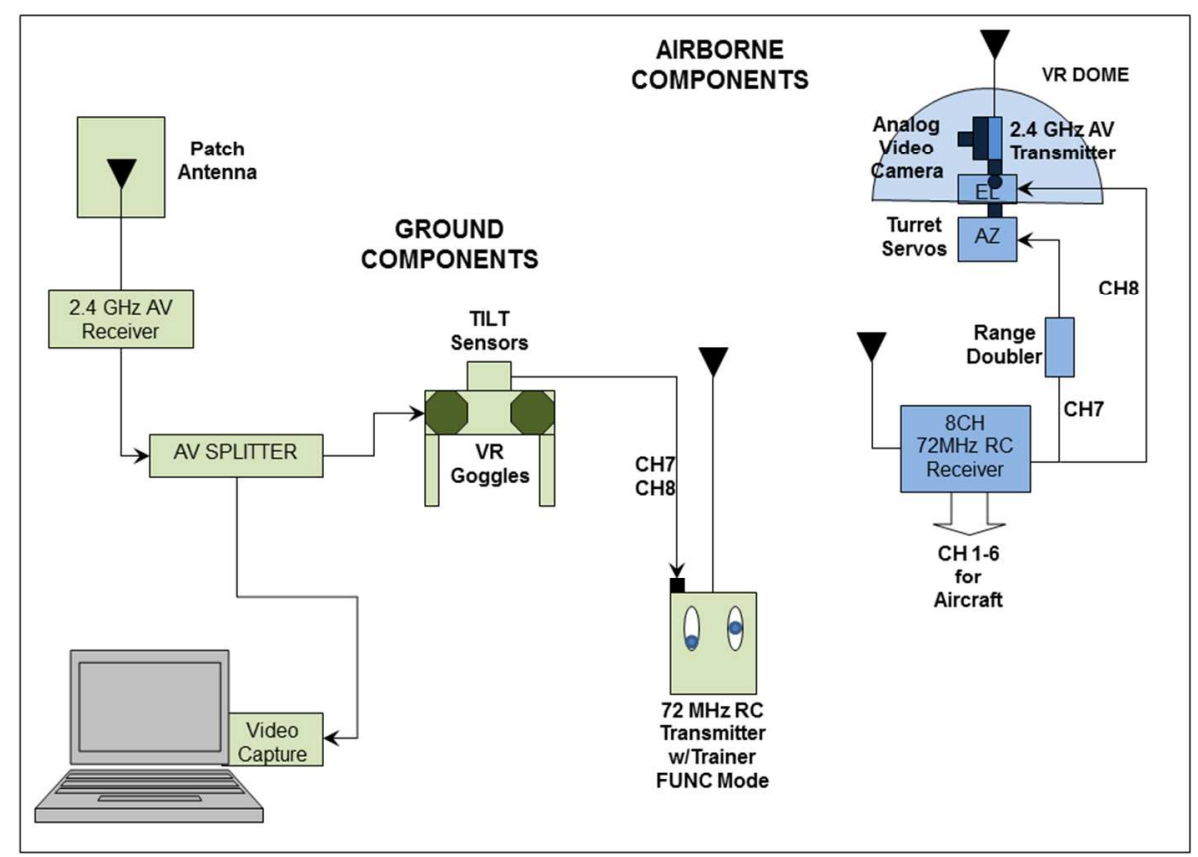

Figure 5: VR Equipment Schematic (2010) 


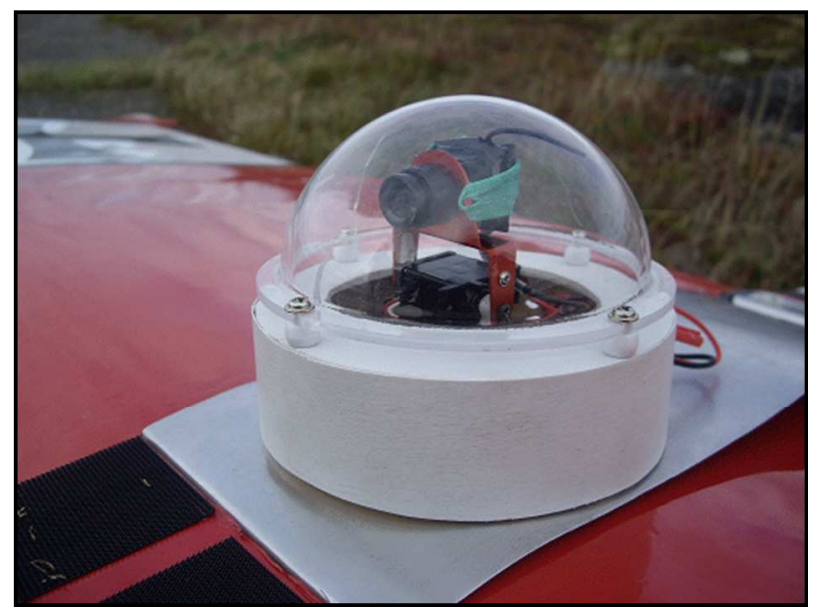

Figure 6: VR Dome Installation (2010) 


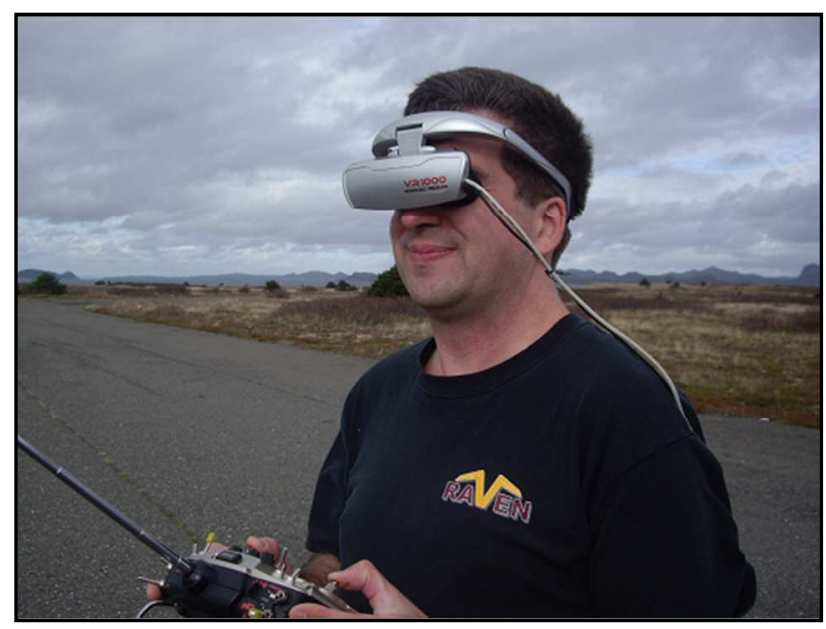

Figure 7: VR1000 Goggles (2010) 


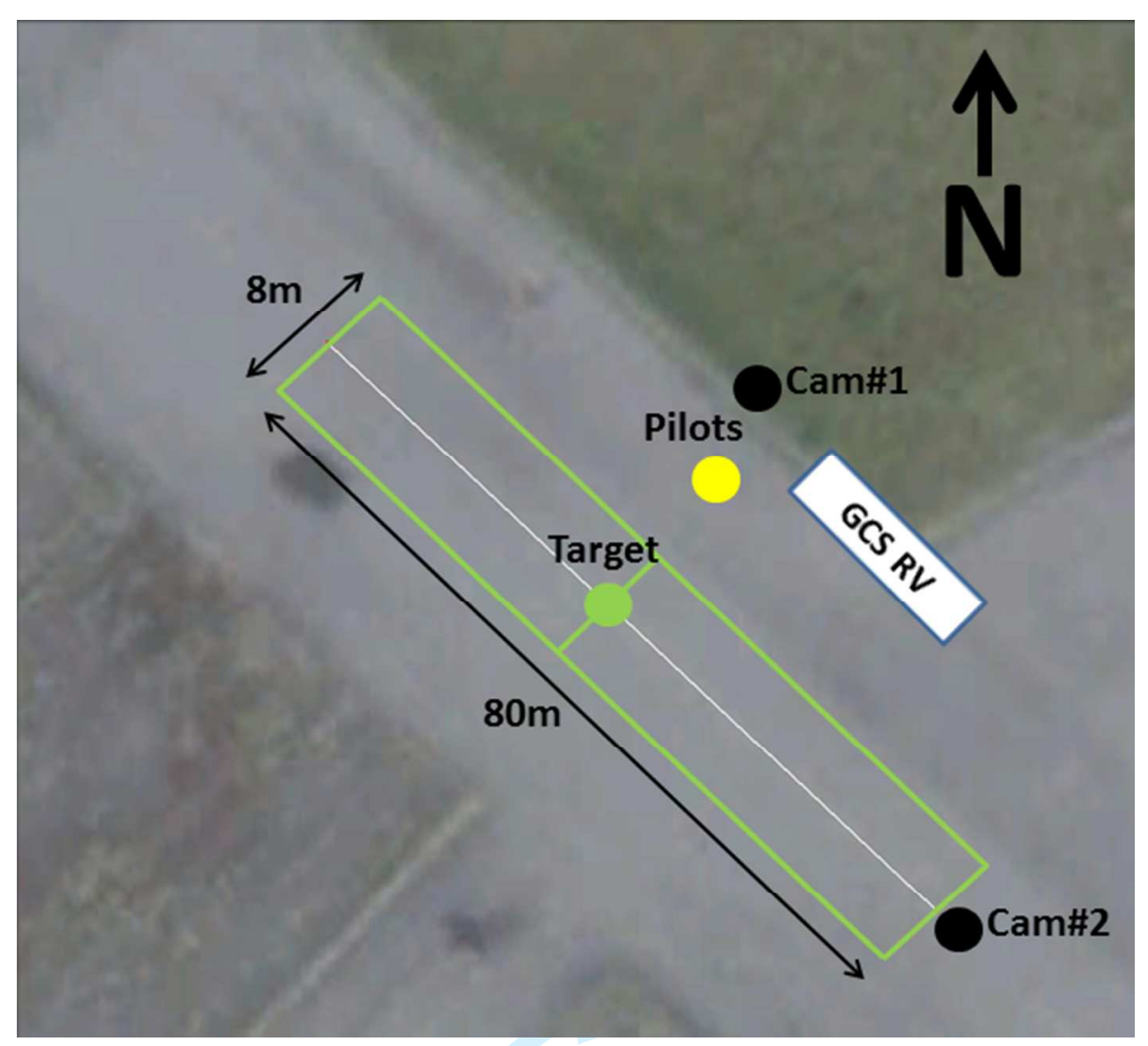

Figure 8: Test Site at Argentia (2010) 


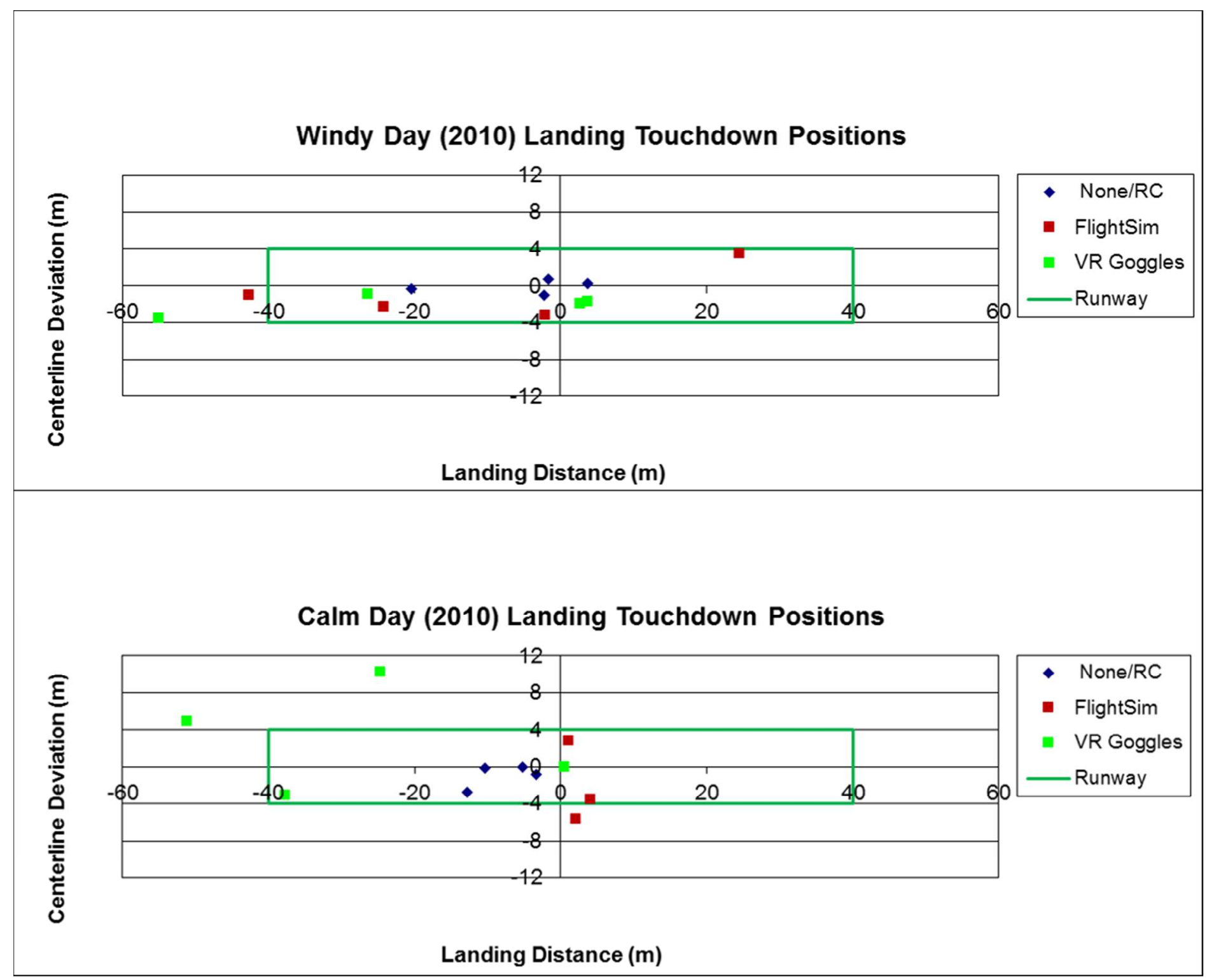

Figure 9: Landing Positions, 2010 VR Experiment 


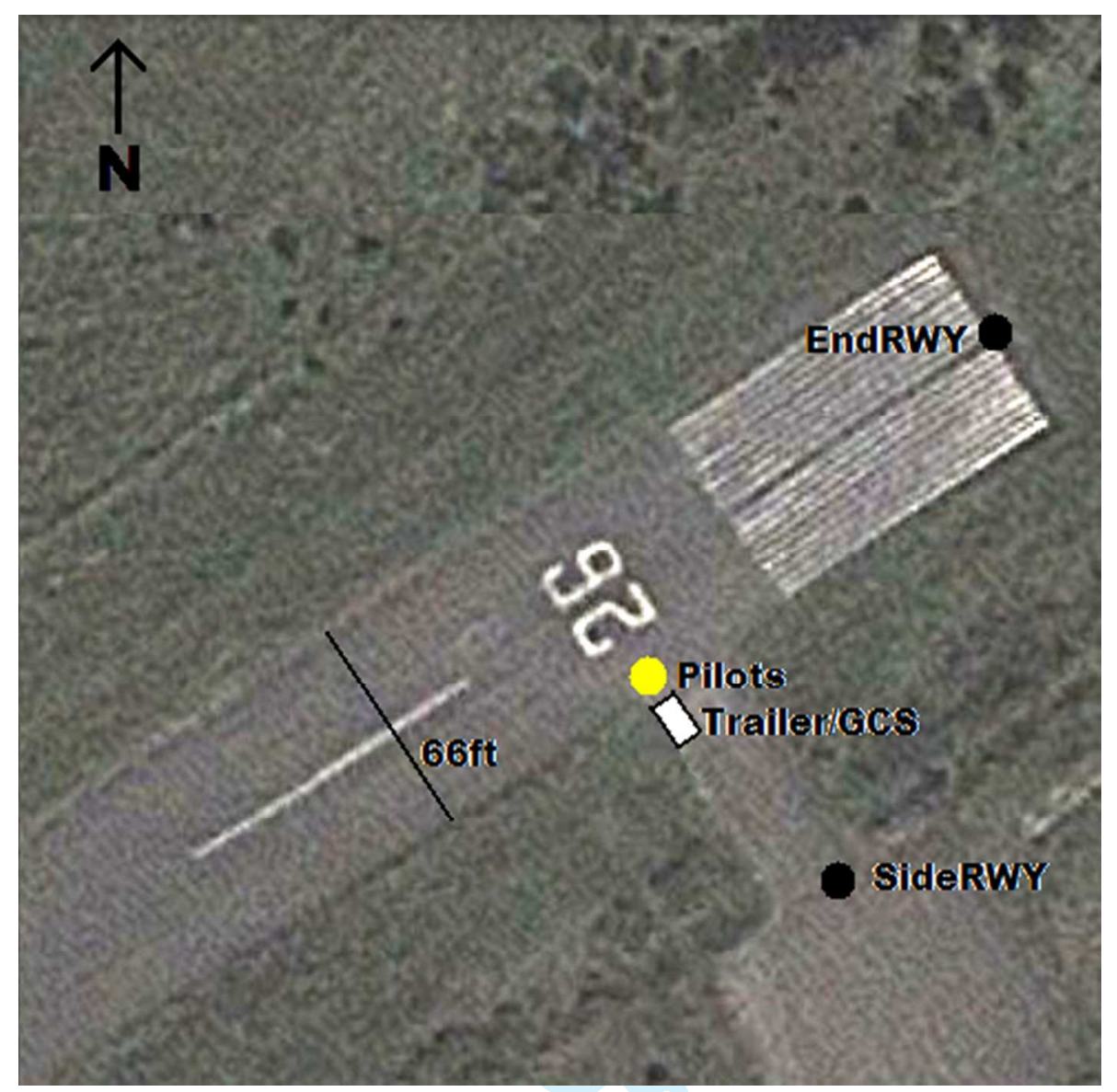

Figure 10: Test Site at Bell Island (2013) 


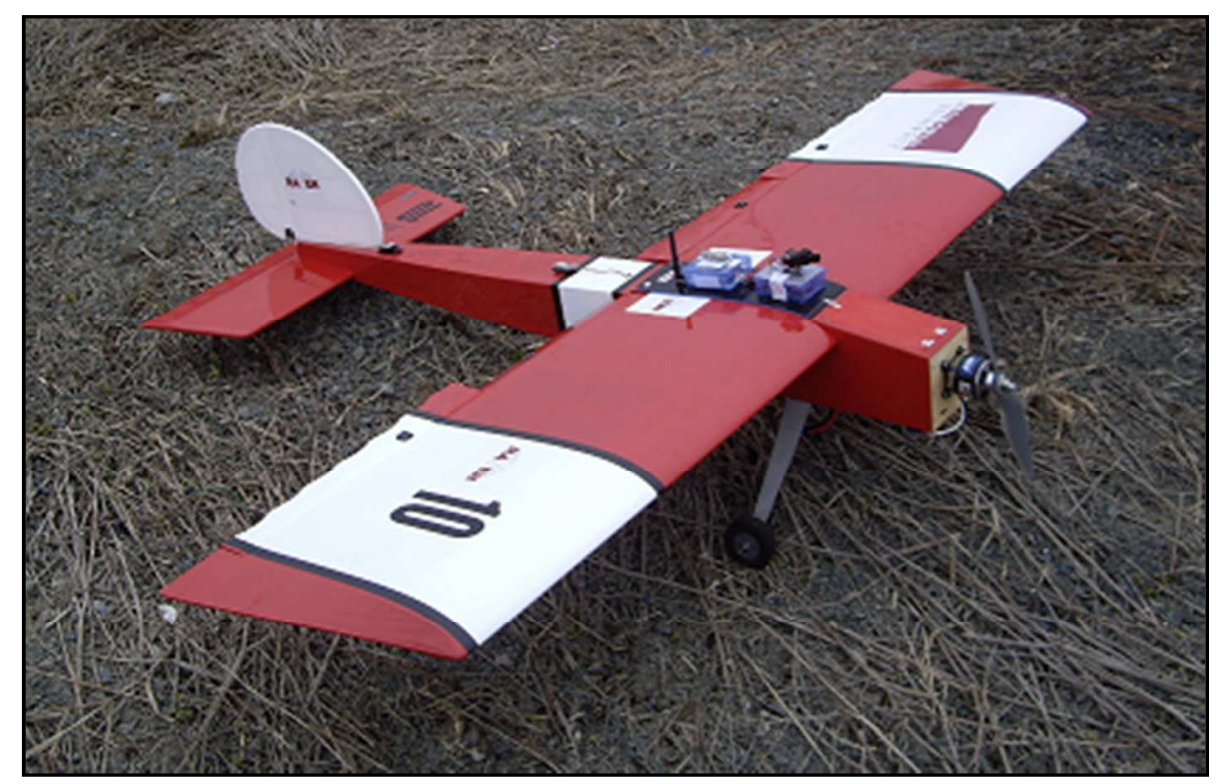

Figure 11: GiantStik\#10 Test Vehicle (2013) 


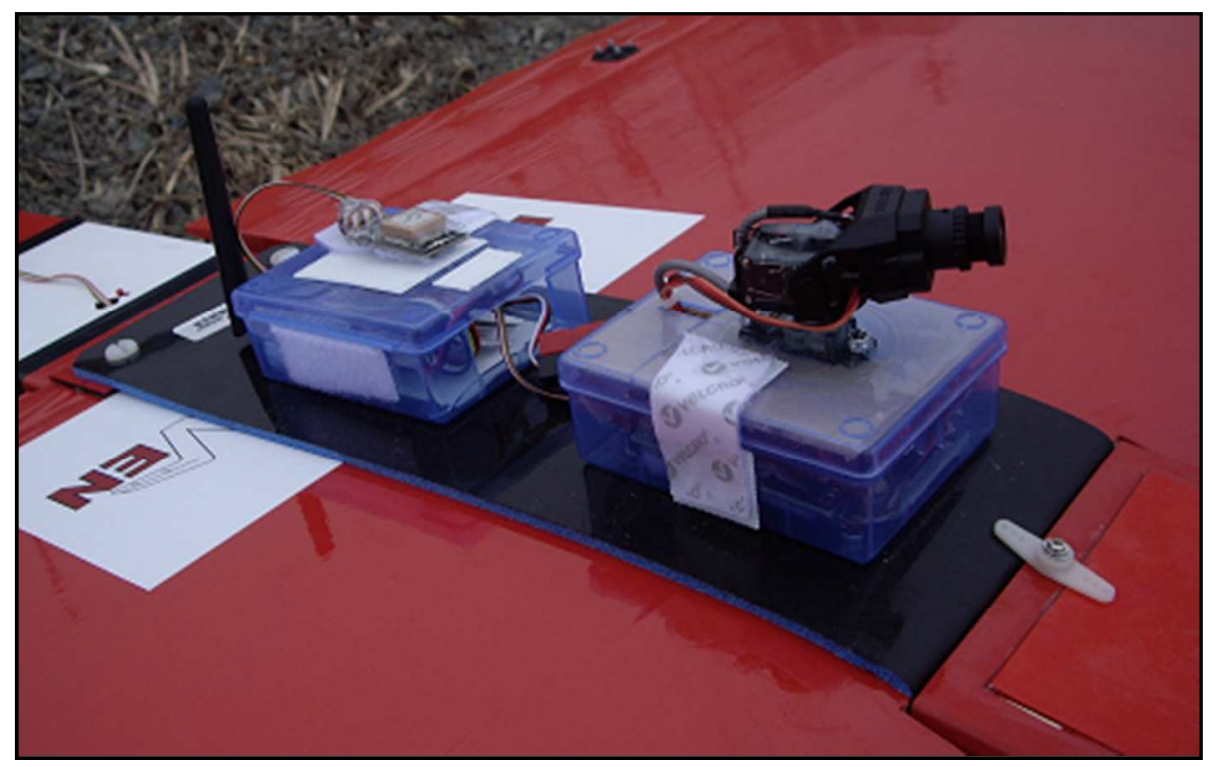

Figure 12: VR Camera and Turret (2013) 


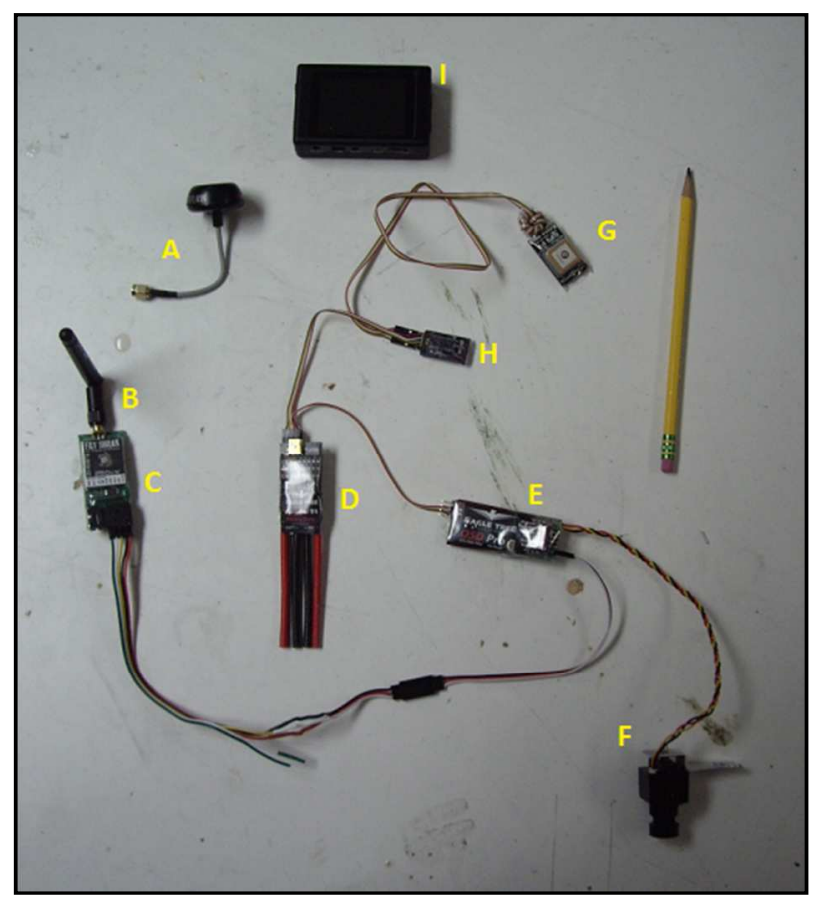

Figure 13: EagleTree FPV Components (2013) 


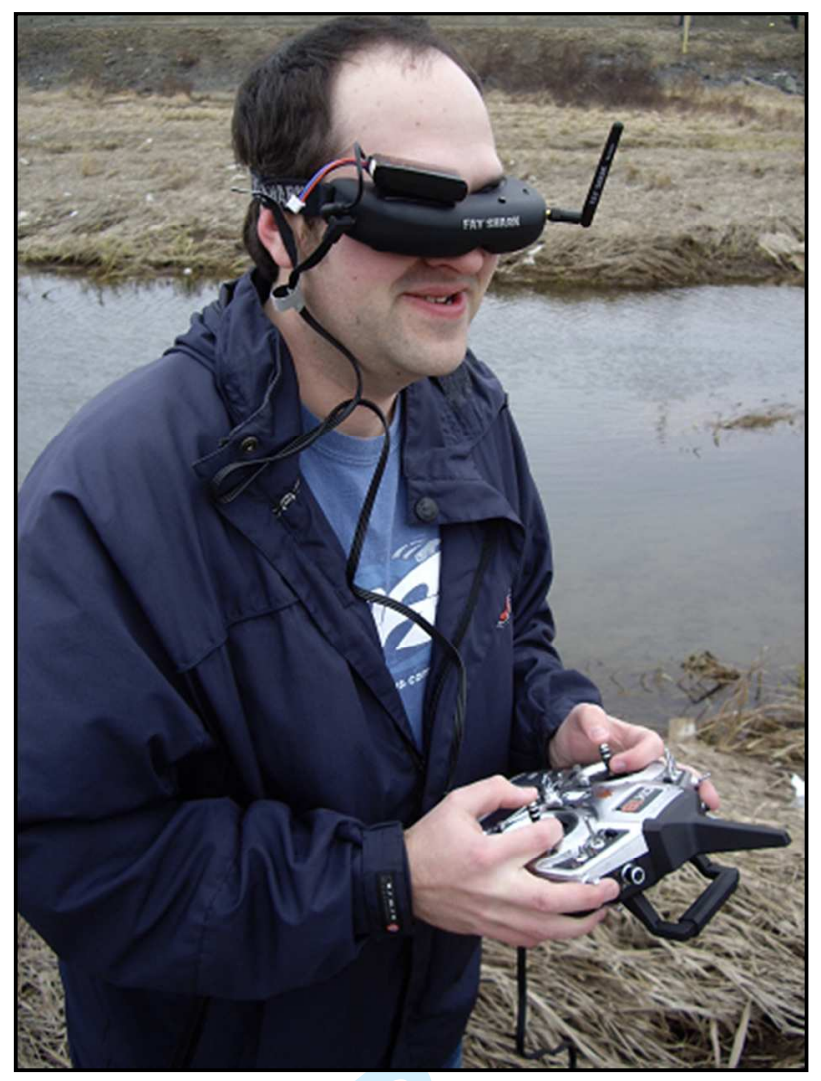

Figure 14: VR Goggles for 2013 Experiment 


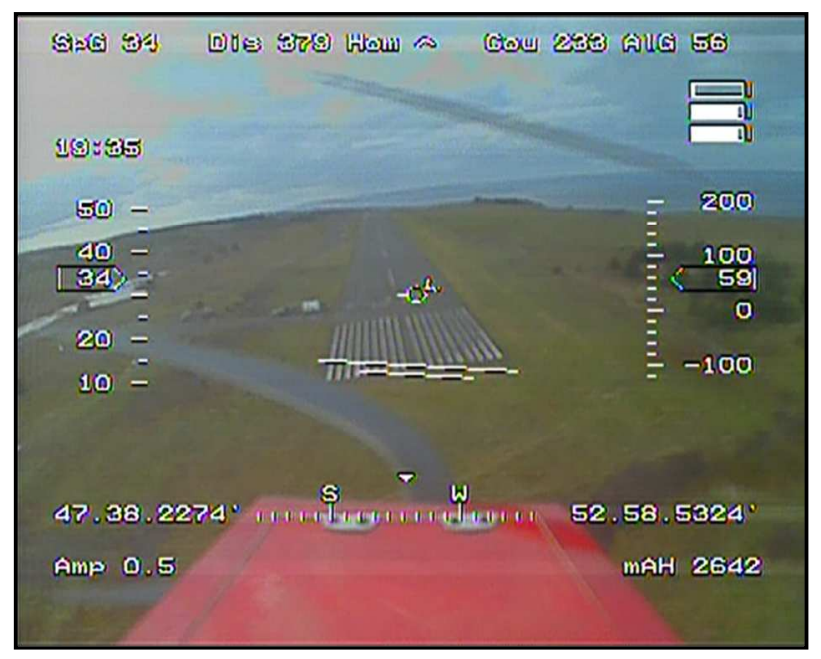

Figure 15: FPV Display with HUD (2013) 


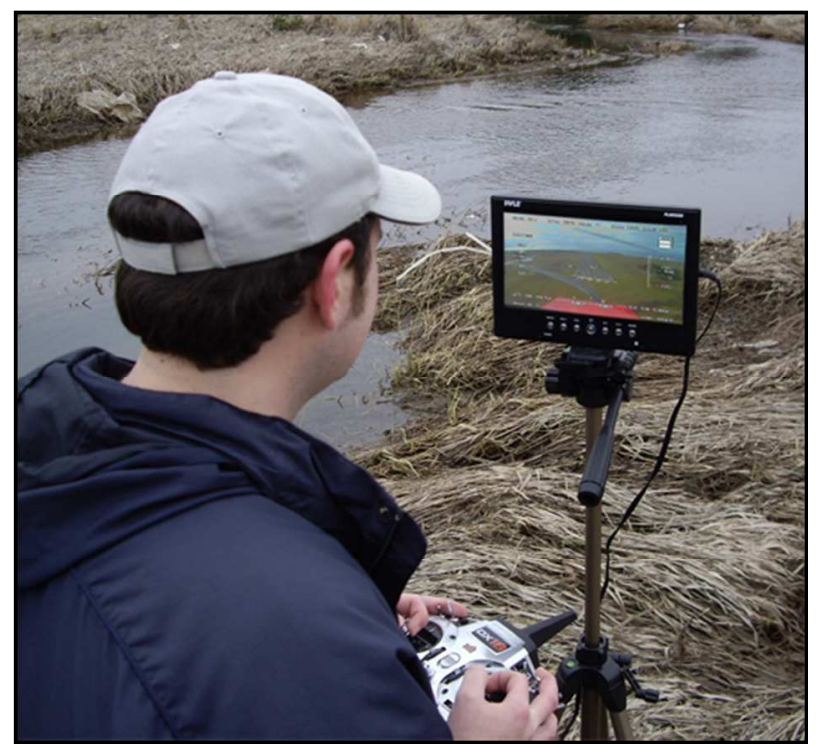

Figure 16: FPV LCD Display on Tripod (2013) 


\section{Combined (2013) Landing Touchdown Positions}

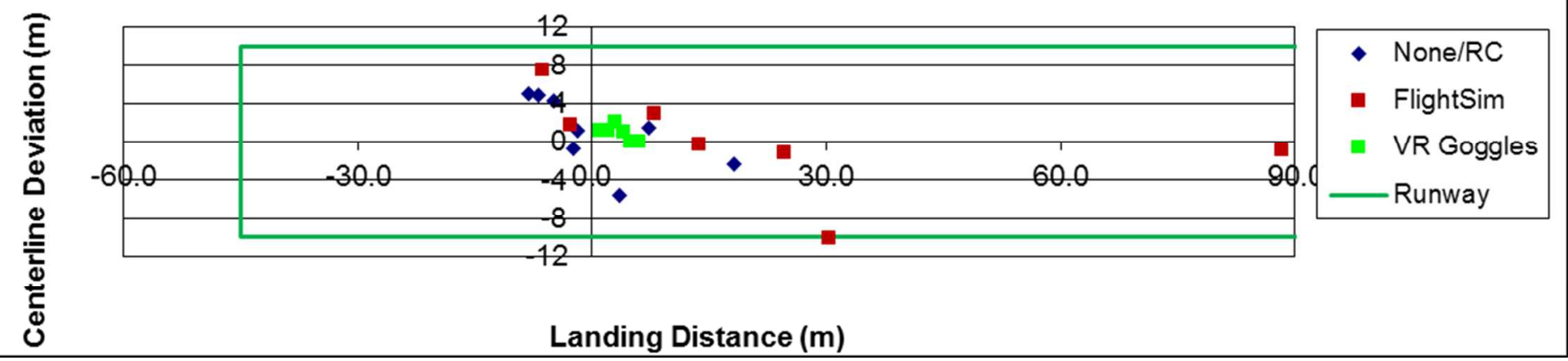

Figure 17: Landing Positions, 2013 VR Experiment 